\title{
COURSE PLACEMENT: ITS IMPACT IN A MIDWESTERN REGION SCHOOL DISTRICT ON ACHIEVEMENT, CURRICULUM, INSTRUCTIONAL STRATEGIES, EXPECTATIONS, AND PERCEPTIONS OF THE PROGRAM
}

\author{
A Dissertation \\ presented to \\ the Faculty of the Graduate School \\ at the University of Missouri-Columbia \\ In Partial Fulfillment \\ Of the Requirements for the Degree \\ Doctor of Education \\ by \\ Jodi A. Glidewell \\ Dr. Bret D. Cormier, Dissertation Supervisor \\ May 2019
}


The undersigned, appointed by the dean of the Graduate School, have examined the dissertation entitled:

\section{COURSE PLACEMENT: ITS IMPACT IN A MIDWESTERN REGION SCHOOL DISTRICT ON ACHIEVEMENT, CURRICULUM, INSTRUCTIONAL STRATEGIES, EXPECTATIONS AND PERCEPTIONS OF THE PROGRAM}

presented by Jodi Glidewell,

a candidate for the degree of doctor of education, and hereby certify that, in their opinion, it is worthy of acceptance.

Dr. Bret D. Cormier, Chair

Dr. Paul Watkins

Dr. Lisa Bertrand

Dr. William Bratberg 


\section{Dedication}

I made the decision in 2014 that I wanted to pursue my doctorate in educational leadership and policy analysis. I made this decision because I wanted to expand my opportunities as a professional and possibly teach at the collegiate level someday. I had

no idea at the time that the journey I embarked on in the spring of 2015 would impact me so greatly.

I would like to thank my family for supporting me through this process. Going away to school as an adult with a career is much different than when you move away from home to start college as a freshman straight out of high school. There are so many considerations of who is going to manage things in your absence. I must first thank my mom, Rosalie Dinwiddie. As soon as I said I wanted to go back to school and that it would require me to be away from my home for two summers, she offered to take care of my pet and do what she could to help. My mom taught me the value of hard work and the importance of education from a very young age.

Next, I must thank my biggest cheerleader, my dad, Larry Glidewell. He asked me many years ago if I was going to get my doctorate and at that time I said no. When I told him I was going to pursue the degree, he was so excited. Hardly a week goes by that he does not ask me how my dissertation is going.

I would like to thank my sister, Auvery, brother-in-law, Craig, nephew, Trenton, and niece, Ireland. Going away to school has made the time that I have been able to spend with my nephew and niece all the sweeter.

Friends are also an important group to thank as a part of this expedition. When we started the summer of 2015 at Columbia, I met people from the Southeast region that 
would become such important parts of my life. I did not know at the time that the four other women who would comprise our local group would become life-long friends and fellow searchers for justice and truth in our respective fields. Misty Chisum, Brandy Hepler, Leanne Hopper, and Millicent Odhiambo are all amazing women and have and will continue to make a wonderful impact on the world at large. This journey was not without its complications. Several of us experienced personal and family health crises during the four years we have spent together. When these would occur, we would support one another and come back stronger than ever. It is imperative that everyone have a group like this when going through this experience and I had the best. 


\section{ACKNOWLEDGEMENTS}

I would like to thank Dr. Bret D. Cormier, my dissertation chair, for his sound advice and thought-provoking questions that made me consider other ideas for my research. I appreciate the fact that Dr. Cormier was willing to serve as my chair after we had completed our comprehensive exams.

I would also like to thank Dr. Paul Watkins. Dr. Watkins, my dissertation cochair, was instrumental throughout my four years in this program of providing humorous insight into the world of education and helping me to understand how research could impact our world and institute change.

Additionally, I would like to thank Dr. Lisa Bertrand and Dr. William Bratberg for serving on my committee. I appreciate Dr. Bertrand's assistance in better understanding how to conduct qualitative research and Dr. Bratberg's love and passion for quantitative research. I would also like to thank Dr. David Stader and Dr. C. P. Gause for their time in teaching our classes the first two years of the program and their assistance with my dissertation.

Finally, I would like to thank all the teachers who took the time to share their

thoughts on the grade-level and college preparatory tracking system. Your insights were invaluable and helped mold this dissertation. 


\section{TABLE OF CONTENTS}

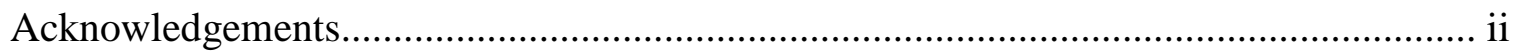

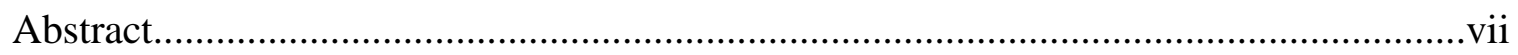

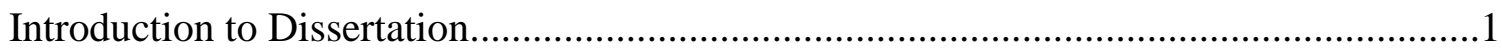

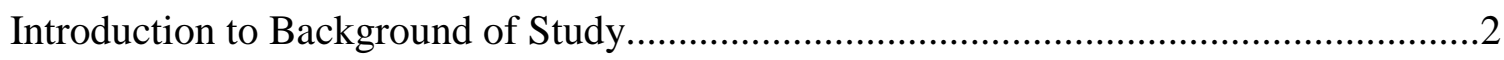

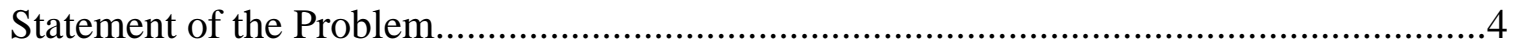

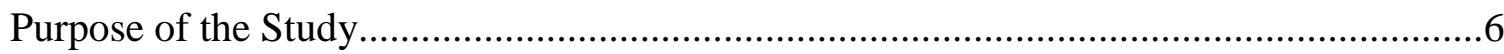

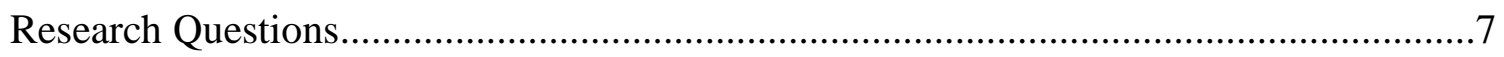

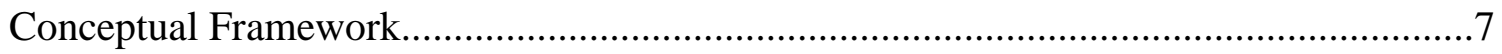

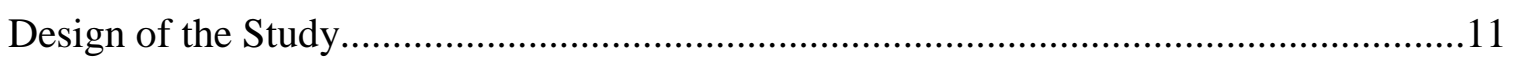

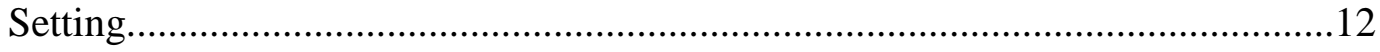

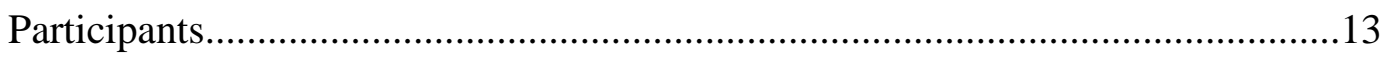

Data Collection Tools............................................................................. 13

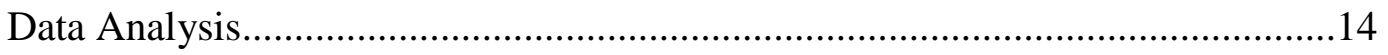

Limitations, Assumptions and Design Controls............................................15

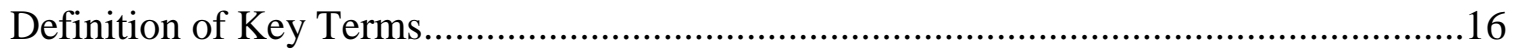

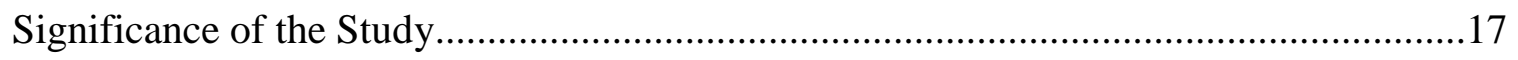

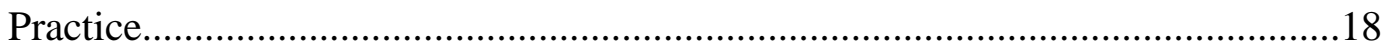

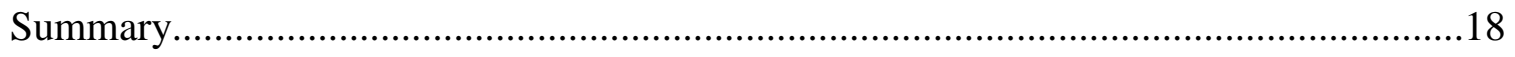

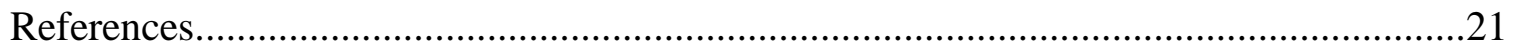

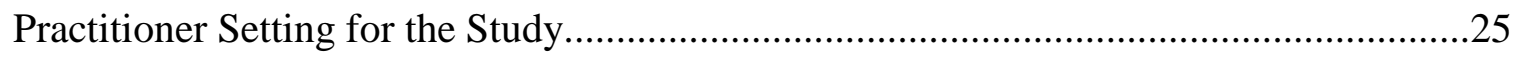

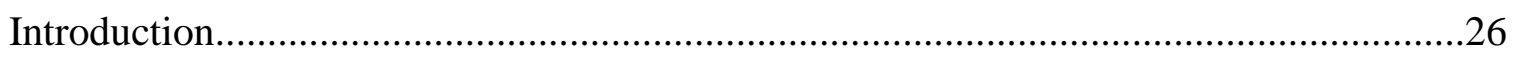

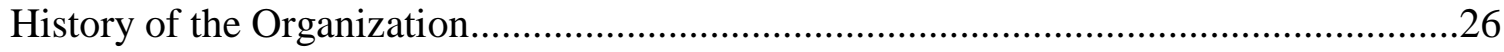


Organizational Analysis.

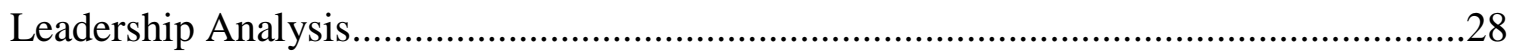

Implications for Research in the Practitioner Setting................................................30

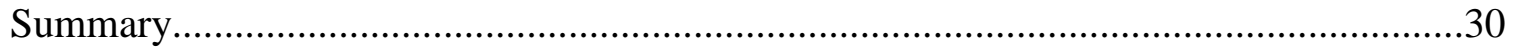

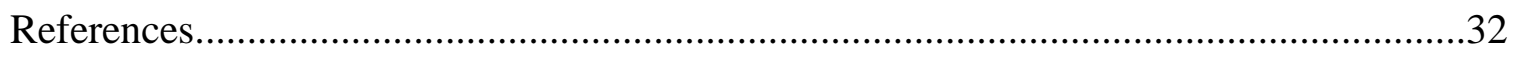

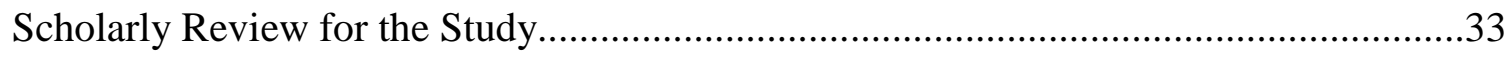

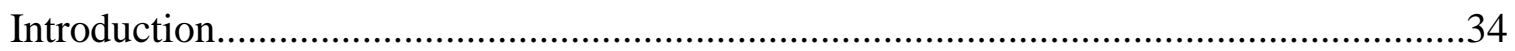

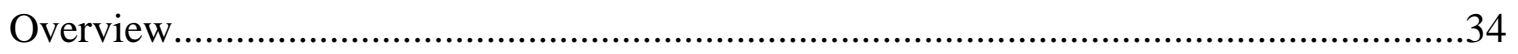

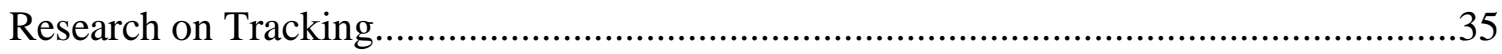

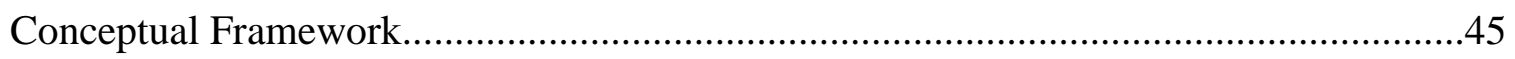

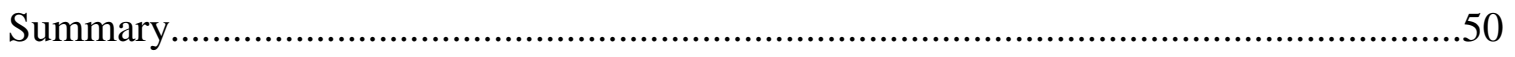

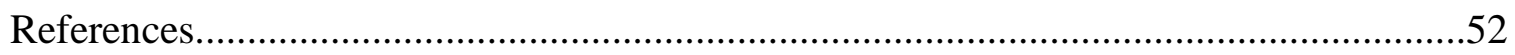

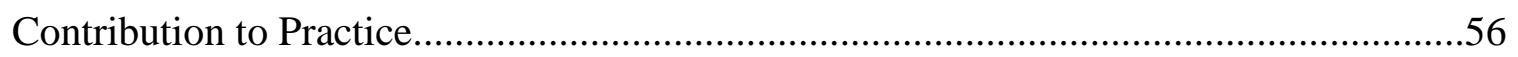

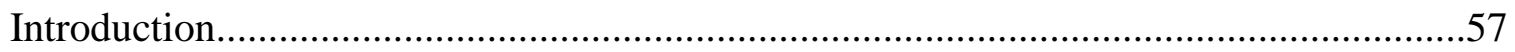

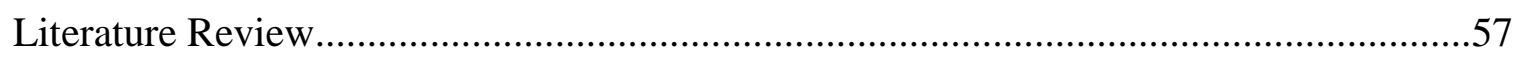

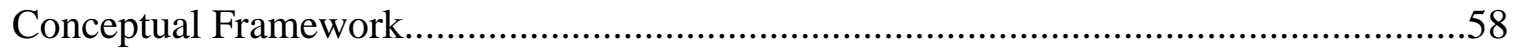

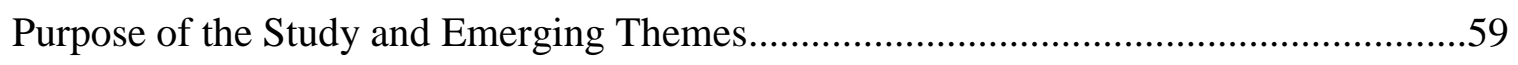

Differences in Instructional Strategies......................................................60

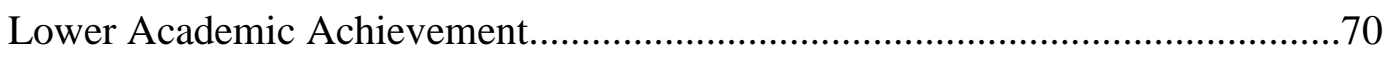

Stigma in Grade-Level Courses............................................................. 71

Differences in Classroom Management..........................................................74

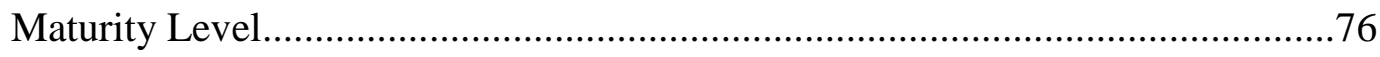

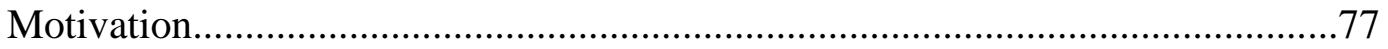


Need for Role Models.

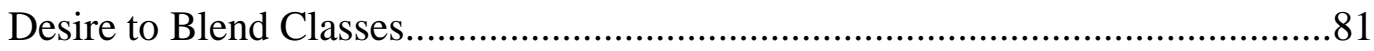

Conclusions, Implications and Recommendations.................................................8

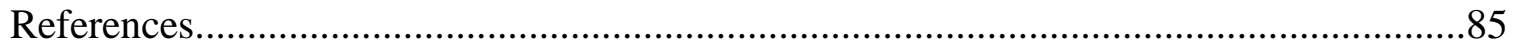

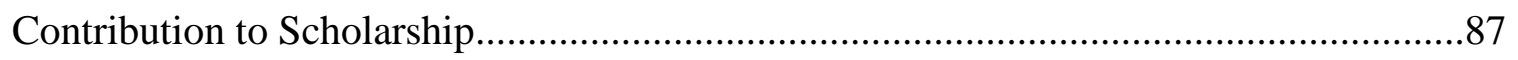

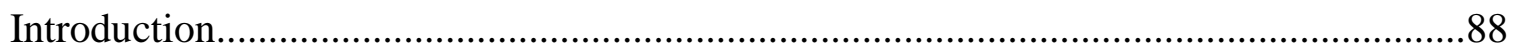

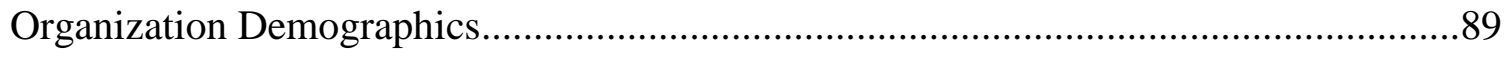

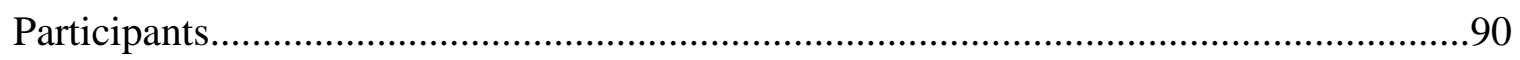

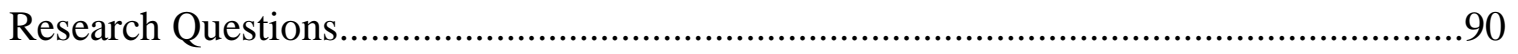

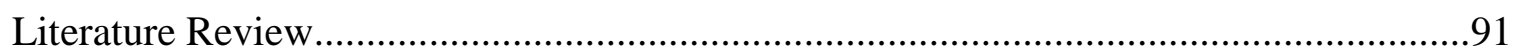

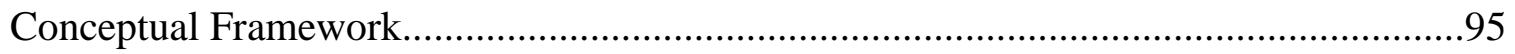

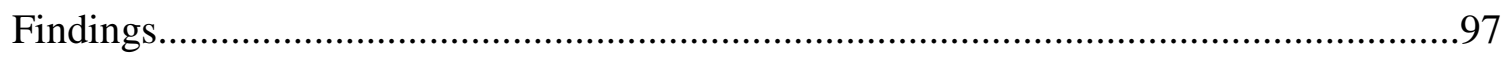

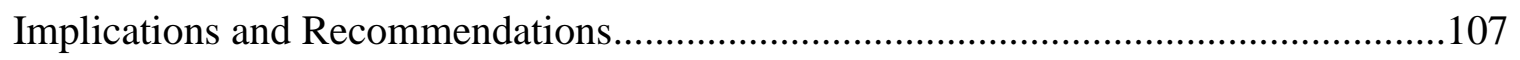

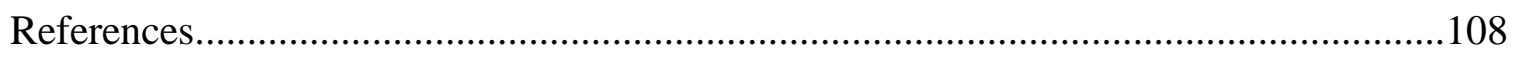

Scholarly Practitioner Reflection................................................................... 111

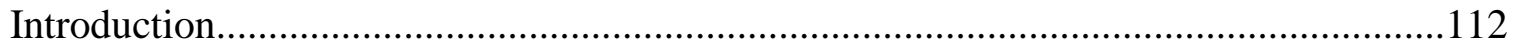

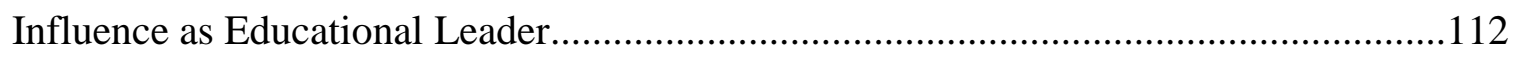

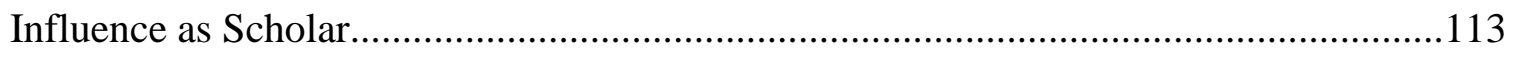

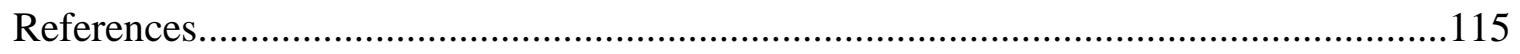

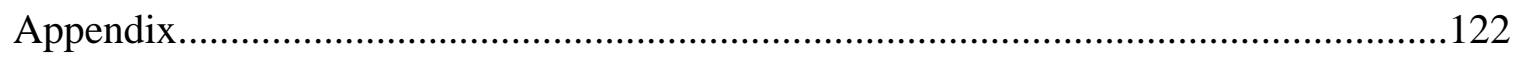

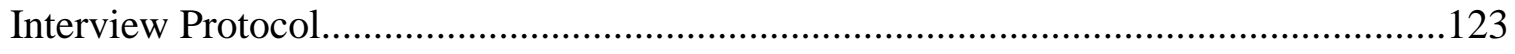

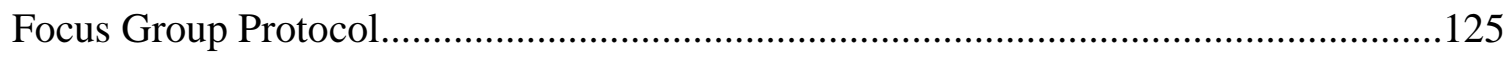

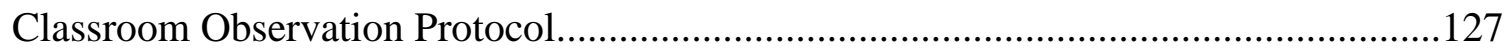




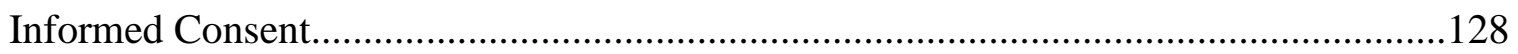

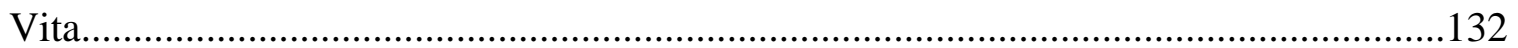


Course Placement: Its Impact in a Midwestern Region School District on Achievement, Curriculum, Instructional Strategies, Expectations, and Perceptions of the Program

Jodi A. Glidewell

\title{
Dr. Bret D. Cormier, Dissertation Supervisor
}

\begin{abstract}
A school district in the Midwestern region uses a tracking system for sorting students into a grade-level or college preparatory track at the junior high and high school levels. This system has been in place for over sixty years. This is an ineffective method of educating students, particularly for those students in lower track classes.

Critical pedagogy, the study of helping people to become free of oppression, and interest-convergence, which advocates that change is implemented when it benefits both groups, were used to study this practice. Focus groups, interviews, and observations of teachers occurred to help answer the following research questions: What impact do various instructional strategies and approaches have on achievement? How does course placement affect instructional behavior and course approaches? What types of instructional practices are being utilized in classroom instruction for both grade-level and college preparatory classes; do they differ and are they equitable?

The findings supported the literature review. Students in grade-level classes are not challenged as much as their college preparatory peers, nor do they receive an equitable education in terms of the instructional practices utilized in the classes. Furthermore, all teachers expressed a desire to blend the classes to help improve discipline, provide role models for students, and to increase academic achievement. It is the recommendation of the researcher that the school district consider doing away with the tracking system as it is an ineffective means of educating the district's students.
\end{abstract}


SECTION ONE:

INTRODUCTION TO DISSERTATION 


\section{System Organization}

\section{Introduction to Background of Study}

The school district, which is situated in the southeastern part of the Midwestern region, has a preschool through twelfth grade program that serves a community of over 16,000. The student body is also made of up of children from two smaller surrounding towns. The school system itself has an enrollment of 3,514 students (DESE, 2016). These students are enrolled at one of eight buildings including a kindergarten which also houses early childhood, three elementaries, a middle school, junior high, and high school as well as a career and technology center, and an alternative school.

The school system is one of the largest employers in the community as it employs over three hundred people. One of the other largest employers is Nichol which is a factory that produces ice cream. The town is diverse in terms of socio-economic status. There are students who live in homes without running water, those who receive luxury automobiles on their sixteenth birthday, and everything in between. A great amount of emphasis is placed on success in sports and musical programs and the town identifies itself with the school. As of 2016, the district had a federal Free and Reduced Lunch rate of $67.6 \% .1 \%$ of the student body was Asian, $34 \%$ black, $4 \%$ Hispanic/Latino, 5\% multi-racial, and 56\% white. Furthermore, the district has an assessed valuation of over $\$ 246,000,000$ and a tax levy of \$3.86 (DESE, 2016).

For well over six decades, the school district has had a tracking system in place for assigning students into courses at the junior high and high school levels. This includes grade-level classes, college preparatory classes, and some Advanced Placement classes at the high school level. Prior to beginning seventh grade, the students are not 
involved in a tracking system to determine course placement. The stated goal of the tracking system is to help provide the differentiation that students need. This system of tracking is ingrained in the district and community. Although the stated goal is to help provide differentiation, concerns exist regarding the effectiveness of the tracking system and teachers' perceptions of students in the various tracks. Decisions as to what course students are placed into are based on academic achievement, teacher recommendation, parental requests, and standardized test scores.

Despite the fact these indicators are used to help determine course placement, the tracking system appears to also have become a means to separate students based on discipline and economic status. This is significant because the Midwestern Region's Department of Elementary and Secondary Education (DESE) has launched the Top Ten by Twenty initiative. This is an improvement effort that aims for the Midwestern region's student achievement to be in the top ten of the United States by 2020 (DESE, 2016). A major point of this initiative is that all students will be college and career ready. These reasons are serious considering students in the Midwestern region must complete standardized tests that are aligned with the Midwestern Learning Standards. The Midwestern Learning Standards define the knowledge and skills that the state has identified that each student needs to know in each grade-level and course to be successful in college and their careers. They are a road map for educators to use in determining curriculum. Furthermore, they are an instrumental component of the Top Ten by Twenty initiative (DESE, 2016). Students taking grade-level courses are supposed to receive instruction that meets the standards outlined by the Midwestern Learning Standards. Those involved in college preparatory classes also receive an 
education that meets the Midwestern Learning Standards while also requiring more rigorous work than grade-level courses do. Those students taking Advanced Placement courses at the high school receive an education that is aligned with the Midwestern Learning Standards while also enabling them to take the Advanced Placement test upon completion of the course.

These standardized tests and standards that all Midwestern students are expected to be able to complete do not differentiate on the material and level of rigor of the assessments. All students complete the same exams even though they may not have been exposed to the same teaching practices when taking grade-level, college preparatory, and Advanced Placement courses. The scarcity of information on teacher perceptions regarding course placement is regrettable and it must be analyzed to help make sound decisions regarding the educational process.

\section{Statement of the Problem}

The mission of the district is, "We ignite; we inspire; we empower" (Midwestern $\mathrm{R}-1,2018$ ). One of the goals of the school district is to improve academic achievement in most grade-levels and subject areas. Other stated goals of the district are to provide more differentiated alternative education programs for students who are working above and below grade-level, to provide professional development for teachers to address the needs of students with special needs, to identify and address facility needs, to have teachers increase the use of student-centered instructional strategies, and to have students demonstrate respect and increase the use of good manners (Midwestern R-1, 2018). While the mission statement and goals are referenced frequently when stating 
what the school district stands for and how it operates, there is limited application when considering the tracking system that is in place at the junior high and high school.

Providing a comprehensive, quality education for all students is an important goal because the Every Student Succeeds Act, (ESSA) which was signed into law in 2015 by President Obama, seeks to ensure success for students and schools by advancing equity by upholding protections for disadvantaged and high-needs student. Additionally, the law emphasizes that all American students be taught to high standards to prepare them to succeed in college and careers and maintain accountability and action so that lowperforming schools will see positive changes (ESSA, 2015). This is an important distinction from the No Child Left Behind Act (NCLB) which was signed into law by President Bush in 2002. NCLB put in place measures that exposed achievement gaps among underserved students. In 2012, the Obama administration began allowing states flexibility regarding some of NCLB's requirements if they provided plans that were rigorous and comprehensive and designed to close the achievement gap, increase equity, improve the quality of instruction, and increase the outcomes for all students (ESSA, 2015).

Despite these changes and the fact that much research supports teachers' expectations and the impact it has on student achievement and growth, there is a knowledge gap regarding the teachers' expectations of students based on their course placement, achievement, curriculum, and perceptions of the program. This study addressed this gap in the literature by conducting classroom observations as well as studying and coding interviews and focus groups that were conducted with teachers regarding their thoughts and expectations of the students placed in various tracks. 
The problem may be localized due to the community's beliefs in the validity of having a program of study that differentiates between grade-level and college preparatory courses. However, there is a possibility that the findings from the study may be transferable to other educational systems, particularly due to the requirements of the Every Student Succeeds Act. Additionally, it may help to resolve the larger educational issue of teachers' hidden perceptions and expectations of their students based on their course placement rather than their present level of academic achievement or character. It may also help address the issue that communities face regarding their true thoughts on course placement. This includes whether they want a tracking system in place to help differentiate instruction or to segregate students based on socio-economic status and race.

\section{Purpose of the Study}

The purpose of the study is to examine the instructional strategies that teachers utilize in grade-level and college preparatory classes and how they impact achievement. Additionally, it will examine their expectations for the students in regards to learning and belonging. The junior high and high school are buildings steeped in history and supported by community members who have certain beliefs about the way a school should be run. These beliefs can impact the way they feel curricular decisions should be made. Dramatic changes to teaching practices and course placement require thorough study and explanations to all stakeholders in this community before they are accepted and considered to be appropriate. If stakeholders are not involved in the process, there is often pushback and the school is portrayed as not caring about its constituents' feelings related to educational issues. 
The researcher desires to have a positive impact on the education that the students of the school district receive while at the same time including key voices and ideas that are often ignored in this process.

The study may also provide information that may be utilized by other educational institutions who utilize a tracking model and an opportunity to explore the research and implications of critical pedagogy.

\section{Research Questions}

The research questions guiding this study are:

1. What impact do various instructional strategies and approaches have on achievement?

2. How does course placement affect instructional behavior and course approaches?

3. What types of instructional practices are being utilized in classroom instruction for both grade-level and college preparatory classes;

3A. Do they differ and are they equitable?

\section{Conceptual Framework}

Research indicates that tracking is detrimental to students and that teachers can have an impact on student achievement (Bernhardt, 2014). However, there is a gap in the literature concerning how course placements affect teachers' expectations and perceptions of the students in their classrooms, particularly whether teachers have lower expectations of students placed in less rigorous course tracks. A gap also exists regarding what types of instructional strategies are utilized in the different tracks. Additionally, students' prior performance can influence which courses they are placed in; this can also impact teachers' expectations and perceptions. The literature review analyzes what 
research has been done within the United States regarding tracking and course placement and looks abroad to see the impact that it has on different educational systems.

This study is important for several reasons including the impact it may have on future course placements in the school system and because critical pedagogy and interestconvergence were employed as the conceptual framework, rather than using Oakes' theory of tracking as much of the existing research does. Ansalone (2010) established the fact that tracking within the school system is popular in many countries, including the United States. In this system, students are sorted into groups based on high, average, or low ability. This method of sorting students became popular at the beginning of the 1900s and many people viewed it as a means to instill American beliefs and attitudes in immigrants. Schools operated as a factory; students were separated into learning groups based on their perceived ability level (Ansalone, 2010). The theme of placing students into courses based on ability level continues today. Archbald and Keleher (2008) assert that the use of tracking in American schools has declined somewhat; however, $80-85 \%$ of high schools in the United States still have ability grouping in their courses.

Much of the research that has been done utilized Oakes' theory of tracking as the conceptual framework. Oakes' framework suggests that disparities exist in education due to placing students in different tracks. Some students, as a result, receive a high-quality education while neglecting others. This theory is rooted in data that shows tracking, assumptions made by schools and faculty members, and students' aspirations are all closely related. Students placed in high-track classes had higher educational aspirations than those in low-track classes (Ansalone \& Biafora, 2004; Bernhardt, 2014; Kelly, 2007; Modica, 2015; Page, 1987). Most of the researchers employed a qualitative methodology 
to study tracking (Bernhardt, 2014; Shaunessy-Dedrick, Suldo, Roth, Fefer 2014). They

interviewed students, teachers, and administrators and primarily used case studies to examine the impact that tracking had on the school as a whole and student achievement.

The researcher studied the practice of tracking through the lens of critical pedagogy and interest-convergence. Critical pedagogy questions the power structures that manipulate rationality and truth. It recommends that teachers should act as transformative intellectuals. Also, critical pedagogy requires that teachers promote ideals that are democratic and give students opportunities (Foley, Morris, Gounari, \& Agostinone-Wilson, 2015). Critical pedagogy has roots in political organizing and has shifted more towards a social and educational movement. Tarlau (2014) argues that there needs to be a deepened understanding of the relationship between social change and education and that it involves three concepts: the role of social movements in building critical consciousness, links between informal education and social change, and the potential for public schools to make connections to larger movements to promote social justice. Additionally, critical pedagogy emphasizes that schools protect problematic social orders and at the same time can be beacons of hope (Vasallo, 2013).

Furthermore, critical pedagogy values freedom, dignity, and generosity while steering clear of indoctrination and exploitation (Lotier, 2017). Freire emphasizes that critical pedagogy is an important component when considering working with an oppressed population; being liberated from oppression is not a gift or an act of selfachievement, rather it is a combination of the two (Freire, 2000). Ford (2014) elaborates by emphasizing that critical pedagogy is a "response to systematic oppression and inequality" (p. 380). He continues to assert that oppression and exploitation occur along 
the lines of identity and that the identities must be mobilized so the oppression can be revealed.

Additionally, interest-convergence examines the impact of the Brown vs. the Board of Education decision which ruled that separate but unequal was inherently unequal in education. Bell's theory of interest-convergence made the assertion that there was no conflict of interest between the rights of whites to not associate with Blacks and the rights of Blacks to associate with whites. His theory contends that the Brown decision was inevitable. However, more recent court decisions have suggested that integration is less feasible and that a higher quality of education for black students may need to focus on improving existing schools (Bell, 1980).

Gilborn (2013) goes further and argues that Bell's theory that racial progress is unusual and typically short-lived. He asserts that the reverse is occurring because white power holders believe that a direct advantage will occur if Blacks are further oppressed. This is especially prevalent during economic down-turns. Gilborn also establishes that black people are more likely to feel the effects of economic depressions more quickly than whites and that this is also prevalent when education policy is being set.

Crowder (2014) asserts that poverty has expanded across America which calls for more opportunities to confront questions of inequity. She argues that this has resulted in regional interest convergence which provides a structure to identify various groups and their points of convergence. These can include items such as power imbalances and funding of public schools. 


\section{Design of the Study}

The researcher conducted a qualitative study that utilized interviews, focus groups, and observations. This method was selected because it allowed for the use of open-ended questions that were designed to elicit the views and opinions of the participants (Creswell, 2014). Additionally, the observations allowed the researcher to examine what instructional practices were taking place in grade-level classes and college preparatory. The results from the focus groups and interviews were analyzed and themes were identified to produce a full picture of teachers' perceptions of course placement and what instructional strategies they implement in their classrooms.

The research involved a bounded case study because it was based around a single entity and one program (Merriam \& Tisdell, 2016). It attempted to answer research questions that asked what instructional strategies were utilized in the various types of courses in one particular school setting. This study was important for several reasons including the impact it may have on future course placement decisions, instructional strategies implemented in the school district and because critical pedagogy and interestconvergence were employed as the conceptual framework, rather than using Oakes' theory of tracking as much of the existing research does. This created a great challenge because course placement has not been studied a great deal through the lens of critical pedagogy and interest-convergence and the sheer number of teachers and students that the findings may influence; over 100 teachers are employed at the buildings involved in the study. 


\section{Setting.}

The study was conducted at a rural junior high and high school located in the southeast Midwestern region. According to the 2010 United States census, the town had a population of 16,318 . $69.95 \%$ of the population was white, $26.20 \%$ was black or African-American alone, $2.01 \%$ were two or more races, and all other races were less than one percent each of the town's population (Census Viewer, 2010).

The district has seen a decline in enrollment over the past five years at the high school. In 2011, the high school had an enrollment of 1,009; 2012 the enrollment was 1,002; 2013 the enrollment was 1,011; 2014 the enrollment was 998; 2015 the enrollment was 975, 2016 the enrollment was 957 students. Enrollment at the junior high has ebbed and flowed over the past five years. In 2011, the enrollment was 522; in 2012, the enrollment was 532; in 2013, the enrollment was 542; in 2014, the enrollment was 504; in 2015, the enrollment was 531, and in 2016, the enrollment was 535 (DESE, 2016).

For the 2016 school year, the junior high and high school had a total of 1,492 students. The district had a dropout rate of $1.6 \%$ in 2016 (DESE, 2016). The individual interviews and focus groups took place in both buildings in an open classroom. Only the participants, and researcher were present during the interviews and focus group sessions. The interviews and focus groups were recorded to allow for the transcription of the sessions afterwards. Observations occurred in the classroom with the researcher scripting what occurred to help identify trends and patterns regarding how instructional strategies were implemented. 


\section{Participants.}

The participants were teachers from both the junior high and high school. The teachers that participated in the research had a varied amount of experience as they will all have the opportunity to participate. An effort was made to obtain a representative sample of the teachers in the district for the focus group and interviews. Years of experience, amount of education obtained, and gender were all taken into consideration. As of 2016, 250 teachers were employed by the district. They earned on average $\$ 41,173$ per year and had an average of 11.6 years of experience. $44.3 \%$ of the teachers had obtained a Master's degree (DESE, 2016).

\section{Data Collection Tools.}

Prior to collecting any data, the researcher gained approval from the Institutional Review Board (IRB) to complete the study. IRB approval was an important component of this project as the research study involved human subjects and their rights and welfare were paramount (U. S. Department of Health and Human Services, 2016). Approval was obtained from IRB, interviews, focus groups, and classroom observations were conducted with those teachers who were willing to participate. Teachers were contacted in person and through email and asked if they were willing to participate in the study.

Both the interview and focus group questions were pilot tested before being used with the faculty. This allowed the researcher to determine if the questions were viable and elicited information that was pertinent to the research questions. Participants in the pilot test included respondents who were similar to those who were likely to participate in the interviews or focus groups. No one who completed the pilot study participated in the actual research study. All participants in the research study completed an informed 
consent form that notified them of their rights, including their right to withdraw from the study at any time. The form also explained that their responses will be confidential and no personally identifiable information will be associated with the results (Fink, 2017).

The interview protocol focused on asking the teachers what types of instructional strategies they implement in their classrooms in a grade-level and college preparatory class. Two junior high and two high school teachers from core subject areas were interviewed. The interviews were recorded and transcribed.

The focus groups had a broader focus regarding the culture and climate that the tracking system has created in the school system. All focus groups were videotaped and transcribed.

\section{Data Analysis.}

A qualitative study requires that the researcher relies on text and an expanded data analysis because the information must be interpreted and validated. This method was selected because the qualitative approach allows for exploring and understanding the meaning of individuals or groups about a problem (Creswell, 2014). The qualitative data obtained from the interviews and focus groups were run through the NVivo coding software to help look for any emerging patterns and insights as well as coding by the researcher and research assistants. All interviews and focus groups were transcribed. Interviews were conducted one-on-one with a participant and the researcher. The focus groups were used to gather opinions about the issues surrounding teacher perceptions of student course placement. This methodology involved groups that range in size from five to eight people so that everyone had the opportunity to participate and also to allow for a range of diverse ideas. Participants were invited to participate in 
the focus group rather than in a public forum where anyone could attend. Questions utilized at the beginning of the focus group were more generic and as time progressed, they became more focused on the research questions (Krueger \& Casey, 2015).

The researcher examined the transcriptions of the interviews and focus groups to find patterns that were transferable and could be generalized. Results of this data were included in the final report along with any appropriate suggestions that were determined based on the findings.

The researcher utilized scripting during the classroom observations. Notations were made regarding what instructional strategies and approaches were utilized as well as the number of times. A total of eight full class periods observed; this included four grade-level classes and four college preparatory classes. The effect size of the strategies was examined using Hattie's (2012) work to determine if more effective strategies were being implemented in the college preparatory classes than grade-level.

\section{Limitations, Assumptions and Design Controls}

The design of the study was limited because only one school system was being studied so results cannot be compared to other districts. Additionally, the researcher is an administrator in the school district where the study occurred. The researcher used NVivo coding to help determine themes that emerged from the interviews and focus groups. Research assistants, who are also participants in the cooperative doctoral program, assisted with the coding to help eliminate any bias since the researcher works for the school district.

Although the researcher has worked for the school district for sixteen years, she is not from the community. Thus, she maintains both insider and outsider status. This was 
a possible limitation in terms of the fact that she has opinions about the tracking system while also serving as a useful tool because she knows who the gatekeepers in the school system are as well as understanding the community and symbolism that is prevalent.

\section{Definition of Key Terms}

Tracking is a system in which students are placed into various courses. This system can be based on academic achievement, teacher request, or student request.

Grade-level is a title of those courses offered at Springville R-1 which address the skills required by the state of Midwestern and the local school board.

College preparatory is the title given to those courses at Springville R-1 which not only meet the requirements of the state of Midwestern but are stated to offer more opportunities for independent learning and critical thinking.

Honors courses and Advanced Placement courses are those offered at Springville R-1 that address the requirements of the state but also require more than college preparatory classes do.

Pygmalion effect is the term that Rosenthal and Jacobson applied when examining how students performed when their teachers were told the students had indicators that they would excel.

Midwestern Assessment Program is the statewide testing system utilized in Midwestern, known by most educators as the WAP test. Seventh graders take the English and math WAP. Eighth graders take the English, math, and science WAP.

End-of-Course exams are the statewide testing system utilized in Midwestern that tests students' performance in Algebra I, Biology I, and English II. 
Critical pedagogy is one of the conceptual frameworks applied to the research. It questions power structures and insists that social justice not be separate from teaching and learning.

Interest-convergence is the other conceptual framework applied to the research. It contends that the Brown vs. the Board of Education decision was inevitable.

\section{Significance of the Study}

Tracking is detrimental to students both in the United States and

abroad. Teachers as a whole are perceived to have lowered expectations regarding students in lower tracks. Additionally, it is believed that there is a sense of futility amongst the students placed in the lower tracks. Legislation such as the Every Student Succeeds Act requires that students receive an education that is rigorous and will prepare them for college and careers (ESSA, 2015). This research is important because it will address issues that may be hidden regarding course placement, particularly whether it is in place to allow for differentiation of lessons or as a means to further segregate the student body.

The school district will need to thoroughly study this information as it emphasizes a pattern of how tracking impacts students. If the district does consider doing away with the tracking system, this study will be a crucial element in critiquing their assertions about the ways the current system is impacting the students and the education they receive. It may also serve as a crucial piece of information if the data obtained from the surveys, focus groups, and interviews indicate positive trends that implementing the tracking system provides. 


\section{Practice}

Furthermore, the research may possibly contribute to the practice of other educational leaders by studying the system of tracking through the lens of critical pedagogy and interest-convergence rather than Oakes' theory of de-tracking. This research will provide a literature review of existing information regarding critical pedagogy while also providing data obtained from the interviews, focus groups, and surveys that may help guide other institutions in making decisions as to whether they want to continue the use of a tracking model. The research will add to the existing literature base as it will explore the theory of critical pedagogy when applied to the interview questions that will be utilized in the focus groups and individual interviews. The use of critical pedagogy will also guide the survey questions that teachers will complete. The use of interest-convergence will allow for decisions to be made as to whether the tracking system is advantageous to all groups. By focusing on two buildings within one school district, themes will become apparent which can provide the opportunity for transferability to other educational institutions. Other institutions may be considering the impact that course tracking has on their system and students and will be able to review the new research and findings that are produced through this study.

\section{Summary}

Research shows that course tracking has an impact on students. Both Oakes' theory of de-tracking and critical pedagogy emphasize that disparities exist in education. While Oakes' theory focuses on the disparities that exist between the education that students receive in the different tracks, critical pedagogy focuses on the power structures that exist in education and the impact of the oppression. 
Missing from the research though is how teachers perceive their students based upon their course placement. This study will help to close this gap in the existing literature and provide direction for school districts that are examining the impact their tracking system is having. Since this is a bounded case study, the researcher will have the opportunity to provide a rich analysis of one school system that may guide future decisions regarding curriculum, course offerings, and student placement in courses. The study will also provide a new lens that tracking may be studied through since critical pedagogy and interest-convergence will be employed rather than Oakes' theory of detracking.

Furthermore, the study will help give a voice to teachers as previous studies have primarily been concerned with just quantitative data about student achievement in various course placements. This study will address the following questions through a qualitative method that includes the use of interviews, focus groups, and observations. This will allow for extended responses that are coded to determine emerging themes regarding teacher perceptions of course placement:

1. What impact do various instructional strategies and approaches have on achievement?

2. How does course placement affect instructional behavior and course approaches?

3. What types of instructional practices are being utilized in classroom instruction for both grade-level and college preparatory classes;

3A. Do they differ and are they equitable?

Answers to these questions will guide the study and may have an impact on future research that may be conducted regarding critical pedagogy and interest-convergence and their implications in a public-school setting. Although the study will follow the format 
of a bounded case study, an opportunity exists for the research to be applied at other institutions who are considering their tracking practices and teachers' perceptions of course placement. 


\section{References}

Ansalone, G. (2010). Tracking: Educational differentiation or defective strategy. Educational Research Quarterly, 34(2) 3-17.

Ansalone, G., \& Biafora, F. (2004). Elementary school teachers' perceptions and attitudes to the educational structure of tracking. Education, 125(2), 249-258.

Archbald, D., \& Keleher, J. (2008). Measuring conditions and consequences of tracking \ in the high school curriculum. American Secondary Education, 36(2), 26-42.

Bernhardt, P. E. (2014). Making decisions about academic trajectories: A qualitative study of teachers' course recommendation practices. American Secondary Education, 42(2), 33-50.

Bell, D. A. (1980). Brown v. board of education and the interest-convergence dilemma. The Harvard Law Review, 93(3), 518-533. doi: 10.2307/1340546

Census Viewer (2010). Sikeston, Missouri population: Census 2010 and 2000 interactive map, demographics, statistics, quick facts. Retrieved from http://censusviewer.com/city/MO/Sikeston

Creswell, J. W. (2014). Research design: Qualitative, quantitative, and mixed methods approaches. Thousand Oaks, CA: SAGE Publications, Inc.

Crowder, P. A. (2014). Suburban poverty and regional interest convergence. Marquette Law Review, 98(2), 763-830.

DESE (2016). Missouri district and school information. Retrieved from https://mcds.dese.mo.gov/quickfacts/Pages/District-and-School-Information.aspx DESE (2016). Missouri learning standards. Retrieved from 
https://dese.mo.gov/college-career-readiness/curriculum/Missouri-learning-

$\underline{\text { standards }}$

DESE (2016). Missouri school directory. Retrieved from

https://mcds.dese.mo.gov/guidedinquiry/District\%20and\%20School\%20Informati on/Missouri\%20School\%20Directory.aspx

DESE. (2016). Top ten by twenty. Retrieved from https://dese.mo.gov/top-10-by-20

ESSA. (2015). Every student succeeds act. Retrieved from https://www.ed.gov/ESSA

Fink, A. (2017). How to conduct surveys: A step-by-step guide. Los Angeles, CA: Sage.

Foley, J. A., Morris, D., Gounari, P., \& Agostinone-Wilson, F. (2015). Critical education, critical pedagogies, Marxist education in the United States. Journal for Critical Education Policy Studies, 13(3), 110-114.

Ford, D. R. (2014). A critical pedagogy of ineffability: Identity, education and the secret life of whatever. Educational Philosophy and Theory, 46(4), 380-392. doi:10.1080/00131857.2013.779218

Freire, P. (2000). Pedagogy of the oppressed. (M. Bergman-Ramos, Trans.). New York, NY: Continuum. (Original work published 1970)

Gilborn, D. (2013). Interest-divergence and the colour of cutbacks: race, recession, and the undeclared war on black children. Discourse: Studies in the Cultural Politics of Education, 34(4), 477-491. doi: 10.1080/01596306.2013.822616

Hattie, J. (2012). Visible learning: Maximizing impact on learning. New York, NY: Routledge.

Kelly, S. (2007). The contours of tracking in North Carolina. The High School Journal, 90(4), 15-31. 
Krueger, R. A., \& Casey, M. A. (2015). Focus groups: A practical guide for applied research (5th ed.). Los Angeles, CA: Sage.

Lotier, K. M. (2017). On not following Freire: Foucault and the critique of human capital. Pedagogy, 17(2), 151-175.

Merriam, S. B., \& Tisdell, E. J. (2016). Qualitative research: A guide to design and implementation (4th ed.). San Francisco, CA: Jossey-Bass.

Modica, M. (2015). My skin color stops me from leading: Tracking, identity, and student dynamics in a racially mixed school. International Journal of Multicultural Education, 17(3), 76-90.

Page, R. (1987). Teachers perceptions of students: A link between classrooms, school cultures, and the social order. Anthropology \& Education Quarterly, 18(2), 77-99.

Shaunessy-Dedrock, E., Suldo, S. M., Roth, R. A., \& Fefer, S. A. (2014). Student's perceptions of factors that contribute to risk and success in accelerated high school courses. The University of North Carolina Press, 98(2), 109-137.

Sikeston R-6. (2018). District information CSIP plan. Retrieved from http://sikestonr6.org/119596_2

Tarlau, R. (2014). From a language to a theory of resistance: Critical pedagogy, the limits of "framing," and social change. Educational Theory, 64(4), 369-392.

United States Department of Health and Human Services. (2016). Institutional review boards frequently asked questions. Retrieved from https://www.fda.gov/RegulatoryInformation/Guidances/ucm126420.htm

Vasallo, S. (2013). Critical pedagogy and neoliberalism: Concerns with teaching selfregulated learning. Studies in Philosophies \& Education, 32(6), 563-580. 
doi:10.1007/s11217-012-9337-0 
SECTION TWO:

PRACTITIONER SETTING FOR THE STUDY 


\section{Practitioner Setting for the Study}

\section{Introduction}

The setting for the study is a rural school district in the southeast portion of the Midwestern region, specifically the junior high and high school which encompasses seventh through twelfth grades. The district has a kindergarten through twelfth grade program and also offers courses through the career and technical center. While the district is willing to try new teaching strategies and examine best practices, some methods are so ingrained in the school and community that they are difficult to change; the tracking system has been in place for over sixty years.

The researcher is a junior high administrator in the school district. She is currently in her seventeenth year with the school district. She taught high school English for six years, was a high school administrator for a year, and has been a junior high administrator for ten years. Although the researcher has a long history as an employee of the school district and resident in the town, she is not a life-long member of the community. She grew up elsewhere and moved to the community when she accepted her teaching position.

\section{History of the Organization}

The school system was founded in the early 1900s. The tracking system dates back over half a century. According to interviews conducted with senior citizens in the community, the tracking system dates back to at least 1955. In 1955, there were three tracking systems in place, including maximum, minor, and regular. Upon learning that the system had been in place since 1955, the researcher began asking various people, including the current superintendent and assistant superintendent, if the decision to 
institute the tracking system was in response to the Brown vs. the Board of Education decision. No one that the researcher spoke to could answer this question, but all were curious as to whether that was the case. The system was condensed into grade-level and college preparatory during the 1990s.

\section{Organizational Analysis}

While all of Bolman and Deal's (2013) frames can fit portions of the school district, the political and symbolic frames are most prevalent throughout the system. The structural frame is merely prevalent in examining the stated roles and positions that people occupy. There is a seven-member school board that is comprised of community members that are elected on a rotating basis. Board members' terms last for three years and they may seek re-election. The school district has a superintendent, three assistant superintendents, and a business services director who oversees all of the finances. Each building, apart from the alternative school, has at least two administrators. One administrator focuses on the building management while another focuses on curriculum and instruction. In those buildings that have more than two administrators, the remaining administrators handle discipline and day-to-day building needs. Each building has a teaching staff and support staff including secretaries, custodians, and cafeteria workers. Although the organization has a mission and well-defined roles, the political and symbolic frames are so important that they can overshadow the hierarchical structure at times.

Bolman and Deal's (2013) political frame is important in the school district because the organization is a coalition and the members have differences. All of these matters are crucial when resources are allocated. This is an important component of the 
school district as the school depends on the local tax base as well as funding from the state of Midwestern to operate. Bolman and Deal state that, "Goals are not set by edict at the top but evolve through an ongoing process of negotiation and bargaining” (pp.190191). This premise is apparent when budget discussions are occurring, and people advocate for the different resources needed for their respective department or area of concentration. Furthermore, different types of power are asserted in the political frame, including position power and reputation. Position power is evident when the superintendent or school board institute a policy or procedure. Reputation and personal power are extremely important in the school district. These individuals are adept at influencing others.

The symbolic frame is important because as Bolman and Deal (2013) point out it is the way humans make sense of the world they live in. Symbols convey meaning that go beyond their obvious uses. There are organizational symbols in the school district such as the importance of the sports teams and values of the community. These values and traditions are passed down through stories and they induct newcomers into the membership. Rituals and ceremonies are especially important in the school district. This encompasses everything from graduation ceremonies and the school song. It is also an important element because systems that have been in place as long as the tracking system can be difficult to change in the school system because they are a part of the fabric of the community.

\section{Leadership Analysis}

Leadership within the school district can be best described as using the situational approach. Northouse (2016) focuses on the premise that different types of situations 
require different kinds of leadership. This involves both a directive and supportive dimension. Leaders must evaluate the followers and determine how well they can complete a goal. In some regards, the leadership of the district is high-directive and lowsupportive; otherwise known as a directing style. This is evident in the budgeting process. Central office administrators give directives to cut the budget a certain percentage and expect building administrators to make it happen. Furthermore, there is a coaching approach where the leadership is high directive and high supportive. In this regard, the leadership focuses on communication between the goals and meeting the followers' needs. This method is implemented when a crisis occurs, such as a faculty member being terminated in the middle of the school year. The supporting approach requires that the leaders are highly supportive and low directive. This approach is utilized more in regard to each building administrator determining how the curriculum should be implemented in each building. Finally, the low-supportive and low-directive style, also known as the delegating approach, is not often implemented in the district. It is occasionally utilized to allow administrators to determine procedures for their own buildings but if problems arise, the leadership will revert back to another style.

Other items such as ethics and the role of gender are also important components in the leadership of the school district. Northouse (2016) states that, "Ethics is concerned with the kinds of values and morals an individual or a society finds desirable or appropriate. Furthermore, ethics is concerned with the virtuousness of individuals and their motives (p. 330). Ethical decisions are an interesting concept in the school district, primarily due to the historical implications of some organizations and previous leaders. 
Issues with equal representation in leadership roles where gender is concerned is also prevalent in the school system. The district has never had a female superintendent and women who become principals face stricter scrutiny than their male counterparts. This point is supported by Northouse's (2016) findings that women are in the pipeline to assume leadership roles, but the pipeline is leaking because women are vastly underrepresented in the top leadership roles. Female administrators in the district have been told frequently, sometimes by community members and other times by district leaders, that people do not want to speak to a woman, they want to speak to a man instead. Issues such as these can further compound matters when questions are being asked about the implications of a program or decision.

\section{Implications for Research in the Practitioner Setting}

The implications for the research in the practitioner setting are profound. Depending on the findings of the interviews, focus groups, and classroom observations, a change in the educational system may need to be advocated. This is extremely important as the tracking system has been in place in some format for over half a century. There are other implications because it will ask questions about people's perceptions of the system. Furthermore, it has implications on a symbolic level as symbols and traditions are extremely important to the Springville R-1 school system. Changes to systems as old as the tracking program can bring about impassioned arguments from those who do not want changes to current practices.

\section{Summary}

The school district where the research is occurring is one that is rooted in tradition. It provides education for students in kindergarten through twelfth grades as 
well as career and technical classes. The tracking system has been in place in the district for over sixty years and the researcher has worked for the district for seventeen years but was not raised in the community. This presents a unique situation as the researcher has both inside and outside status within the school district. 


\section{References}

Bolman, L. G. \& Deal, T. E. (2013). Reframing organizations: Artistry, choice, and leadership. San Francisco, CA: Jossey-Bass.

Northouse, P. E. (2016) Leadership Theory and Practice. (7th ed.) Los Angeles, CA: SAGE. 
SECTION THREE:

SCHOLARLY REVIEW FOR THE STUDY 
Literature Review: Tracking and its Impact on Students

\section{Introduction}

For well over six decades, the school district has had a tracking system in place for assigning students into courses. The tracking system includes grade-level classes, college preparatory classes, and some Advanced Placement classes at the high school level. The tracking system begins at the junior high. The stated goal of the program is to help provide differentiation that students need. However, concerns exist regarding the effectiveness of the tracking system and individual teacher's perceptions. It is significant because the Midwestern Department of Elementary and Secondary Education (DESE) has launched the Top Ten by Twenty initiative which is an improvement effort that aims for Midwestern student achievement to be in the top ten of the states by 2020. A major point of this initiative is that all students will be college and career ready (DESE, 2016). While much research has been done regarding teachers' expectations and the impact it has on student achievement and growth, there is a knowledge gap regarding the teachers' expectations of students based on their course placement as well as the instructional strategies employed in the different types of courses. This study will address this gap in the literature by observing classes, studying and coding interviews, and holding focus groups that will be conducted with teachers regarding their thoughts and expectations of the students placed in various tracks.

\section{Overview}

The researcher will be conducting a qualitative bounded case study that utilizes interviews, focus groups, and classroom observations. This study will attempt to answer the following questions: 
1. What impact do various instructional strategies and approaches have on achievement?

2. How does course placement affect instructional behavior and course approaches?

3. What types of instructional practices are being utilized in classroom instruction for both grade-level and college preparatory classes;

3A. Do they differ and are they equitable?

This study is important for several reasons including the impact it may have on future course placements in the school system and because critical pedagogy and interestconvergence will be employed as the conceptual framework, rather than using Oakes' theory of tracking as much of the existing research does. This creates a great challenge because course placement has not been studied a great deal through these lenses.

\section{Research on tracking}

Current research indicates that tracking is detrimental to students and that teachers can have an impact on student achievement. However, there is a gap in the literature concerning how course placements affect teachers' expectations and perceptions of the students in their classrooms, particularly whether teachers have lower expectations of students placed in less rigorous course tracks. Additionally, students' prior performance can influence which courses they are placed into; this can also impact teachers' expectations and perceptions. The literature review will analyze what research has been done within the United States regarding tracking and course placement and will also look abroad to see the impact that it has on different educational systems.

Ansalone (2010) emphasizes that for almost a century schools have assigned students to various classes based on their "perceived academic ability" (p.3). This differentiation often results in unequal access to knowledge and different treatment of 
students. Ansalone reviews the fact that there are various forms of tracking that are utilized in schools. There are classes for gifted students which only admit those students based on their perceived ability and there are also special education classes offered for students with learning disabilities. However, most of the tracking in United States schools is between-class groupings. This consists of sorting students into classes of high, average, or low ability. This system was implemented at the beginning of the 1900 s to Americanize immigrants and Southern Blacks who were moving into cities. The reasoning for creating a tracking system was that offering differentiated education would "appropriately socialize the various groups into work roles suitable to their class standing" (p. 4).

Additionally, Ansalone (2010) examines the pros and cons of the tracking system. He asserts that some people perceive tracking to increase societal efficiency by utilizing human resources properly. The self-development rationale views it as a pedagogical device that assists with learning and improves student self-concept when students are grouped homogeneously. Opponents argue that tracking is an attempt to legitimize the stratification system. Lower track classes have a disproportionate amount of Blacks and Hispanics students enrolled and these courses are characterized by the inferior education they provide. Opponents also view tracking as an attempt to instill values and attitudes that are considered important in the workforce such as acceptance, discipline, and humility.

Ansalone (2010) expresses these beliefs and found that there is little support for the assertion that tracking improves academic achievement of students. He also found that the benefit to higher-track students is likely the result of the presentation of the 
curriculum in a different way and increased teacher expectations. There is also an influence of class and race on track placement. Tracking generally separates students along racial, ethnic and socioeconomic lines. Ansalone also emphasizes that teachers believe that the use of tracking allows for a differentiated educational opportunity while others get enrichment and remediation as needed. Some teachers also prefer tracking because it is a classroom management tool.

Marzano (2003) examined the impacts of various types of instructional strategies on student achievement. He found that in classes where students identified similarities and differences, summarized and took notes, and where the teacher reinforced the students' efforts and provided recognition there was a positive impact on their achievement.

Ansalone and Biafora (2004) found that the research continues to show that children from lower socioeconomic families are more likely to be held back in school and fail to complete their education. Even though the research shows that tracking hurts student achievement, the practice continues to be used broadly in American schools. They focused on the attitudes and perceptions of 124 elementary teachers in New York public schools and explored their perceptions of the advantages and disadvantages of tracking. They found that the teachers' reasons for supporting the tracking system were more closely aligned with classroom management issues. During their study, Ansalone and Biafora found that many of the teachers surveyed were tracked when they were in school and placed in the higher track.

Bernhardt's (2014) work goes further and emphasizes that few studies pay attention to the influence that teachers have on students' trajectories. Although he states 
that many schools have embraced de-tracking strategies and are attempting to increase enrollment in honors courses, more needs to be done to study the role of teachers in helping accomplish this goal. Using Oakes' theory of de-tracking, Bernhardt found that the teachers had a high level of autonomy in making course recommendations for students. However, this did not come from the teachers' familiarity with students' academic abilities. Instead, it came "from ill-defined expectations, poor communication, and a lack of clear administrative policies" (pp. 41-42). This occurred even though the teachers considered test scores and grades when making their recommendations. They also acknowledged taking into consideration motivation, interest in the subject, and work ethic when determining course placement. The teachers also did not follow a predetermined set of standards or assessments when making their decisions which resulted in arbitrary placement.

Archbald and Keleher (2008) emphasize that approximately $80-85 \%$ of United States high schools use ability grouping in courses and that while tracking has many detractors, de-tracking also receives criticism. These criticisms include questioning the impact of heterogeneous grouping. Tracking in school districts is based on varied criteria; teacher recommendations are largely important but there is inconsistency and variability in outcomes for students. This raises questions about fairness and equity. Morris (2005) also explored how teachers perceived and interacted with their white students in a predominately minority school in Texas. He found that the students' interpretation of their socioeconomic status was a result of how their teachers interpreted their whiteness and how they reacted to the students academically. He found that the teachers related academic ability to social class. The teachers used the term 'middle 
class' to refer to students who they felt were intelligent. The term 'poor' was used to describe those students that had more obstacles to overcome in their academic pursuits. Modica (2015), however, asserted that the practice of tracking allows racially mixed schools to maintain segregated classrooms. In speaking with students, Modica learned that several students associated being white with academic success. She found that the long-term practice of tracking created racial boundaries among the students, silenced minority students who were in honors courses, and limited the educational opportunities for all students. Efforts to de-track resulted in positive outcomes for all. Academic achievement and variances in curriculum are important attributes to consider when studying tracking. Page (1987) found that in lower and regular track classes, curriculum differentiation is not an equitable response to students' interests. Lower track classrooms receive a basic education and higher track classes receive enrichment and get the opportunity to participate in a variety of activities and experiences. Curriculum differentiation in schools with a tracking system is actually a sociocultural and political process. When Page began studying two high schools, she found that poor and minority students were overrepresented in lower track classes. The teachers felt that this separation was important for academic and behavioral concerns because they felt the students did not behave appropriately in class. Teachers' perceptions of the students' social class characteristics were reinforced in the classroom. Those students in the lower track received an education that focused on basic skills, respect, punctuality, and limited discussions. Those in the higher-level track were exposed to a more rigorous curriculum that promoted college readiness. 
Kelly (2007) analyzed school tracking policies in North Carolina high schools. The schools in the study were selected from a stratified sample of schools that included the highest scoring to the lowest scoring in terms of academic achievement. Placement of a large proportion of students in higher level courses is often based on social stratification. In North Carolina, around half of the total racial segregation amongst the students is due to segregation within the school systems. Kelly found that the criteria used to place students into courses varied greatly. Although many schools allowed students to enroll in any course they wanted, they were placed based on eligibility that was set by the school system. He found that understanding the policies that promote tracking is the first step to improving implementation of tracking. He also found that the research on tracking is disconnected from school improvement efforts when the relationships between school policies, organizational dimensions of tracking, and student outcomes are understood.

Student's perceptions about the implementation of a tracking system are important to consider as well. Karlson (2015) studied how students perceive the tracking system and argues that high school students view their track placement as a signal of their abilities, and they respond to it by adjusting their own expectations. She examined the consequences of placements in various subjects and investigated the effects of consistent versus discrepant track placements. Results from her study showed that the changes in expectations of students taking honors courses are larger than those in general courses; students tended to regulate their educational expectations based on their track placements. Karlson found that being placed in honors classes in high school positively affected students' expectations. In addition to the impact that tracking has on 
expectations, it has an impact on the stratification of group membership for the students as well as social labeling that is based on cultural assumptions about the individual student's abilities.

Kelly and Carbonaro (2012) went further and attempted to understand the teacherstudent relationship and how teacher expectations of student performance impacted their academic achievement. They found that teacher in higher track classes had higher expectations than the teachers in lower track classrooms. They found three ways in which higher track placement impacted teachers' expectations of their students. First, they believed students identified themselves as college bound and that created consistency in their behavior and performance. Second, the students engaged in similar experiences in other classrooms that teachers viewed as likely to increase their chance of going to college. Third, they found that teachers rely on social categories to define and label students, despite behavior and performance. Teachers found those students in low track classrooms to be frequently disruptive and inattentive due to the lack of incentives for performance in these classes. Furthermore, there was a tendency to be less engaged in school to improve their sense of self-worth. The teachers in low-track classes responded negatively to teaching these courses as well and there was a pattern of negative interactions between them and the students.

Research has also been conducted outside the United States about the impact a tracking system has on education. This research has primarily been conducted in Belgium with a small portion also written about the Chinese educational system. The researchers in these studies exercised a variety of theoretical and conceptual frameworks. This also included a sense of futility and an inequality hypothesis. Much of 
their methodology was qualitative. They found that those students placed in the technical track experienced a greater sense of futility than their peers placed in the academic track. These researchers also found that teachers felt that students placed in the technical track were not as diligent in doing their homework. Researchers in China had findings based on where children lived. Those in urban areas had more educational opportunities than those in rural settings. This included students in both the lower and higher educational tracks.

Van Houtte and Stevens (2015) argue that tracking yields negative consequences for those students in lower tracks. In Belgium, tracking is commonly organized between schools. Schools in Belgium offer an academic track or vocational track. They found that lower track students who are confronted with higher track students in the same school are more likely to lose their faith in the school system and not work as hard. Those students in lower tracks are more likely to have a sense of futility; they defined this as having no control over success or failure in the school system. They often feel that the school system works against them and that luck is required to succeed.

Van Houtte, Demanet, and Stevens (2013) emphasize that past research about tracking mainly showed the impact of the different tracks on students' achievement and behavior. Less attention was paid to the impact of the track placement on teachers' perceptions and expectations regarding the students. They examined if teachers' evaluations of students' cognitive abilities, effort in class and completion of homework varied by track, and whether the teachers' perceptions of the students were based on the students' background, resistance to school, or by labeling of students in the tracks. They found that the teachers perceived students in lower tracks as less able and less diligent 
about completing their homework because of their cognitive abilities and poor behavior. They determined that the teaching culture needs to become less pessimistic, especially regarding those who teach in the vocational track. This will allow the vocational track to attract other students as it is currently viewed as a negative choice when students have not reached the standards necessary to be placed in the academic track.

A tracking system is also utilized in Chinese schools as students are placed in an academic or technical track upon completion of middle school. Baoyan and Minggang (2015) emphasized that the distribution of opportunities in high schools in China is based on the population size. They examined the opportunities within Q County, Gansu Province and found that tracking existed along the lines of sex and socioeconomic levels when students graduate from middle school and are placed in the tracking system. In China, the high school education system links compulsory education and higher education. A variety of different high schools exist, and they have different requirements and standards. They found that the father's level of education was the main factor in determining what high school opportunities the child participated in.

In addition to tracking, a great deal of research has been conducted on teachers' expectations of their students. Rosenthal and Jacobsen (1992) emphasize that teachers often believe that middle class children will do well in school while lower class children will struggle. They tested the idea that in a classroom where the teacher expected greater growth from students the students would show more growth. Oak School, where the study occurred, had a policy of sorting the students into tracks based primarily on their reading ability. A disproportionate number of Hispanic children were in the lower 
groups. Although placement into a particular track was based on reading level, the teachers were able to make recommendations as well. The study required that the students participate in an intelligence test. They were later given a posttest as well to measure if there had been any change. In this experiment, the teacher was the agent of change. The teachers had been given a list of twenty percent of their students and told those children were about to excel, but they could not discuss that with the children or their parents. The children on the lists had been selected by a table of random numbers. The difference between the children marked for growth and the control children was actually in the mind of the teachers. Therefore, they surmised that teachers' expectations can be responsible for the students' gains. The researchers referred to this as the Pygmalion effect where an increase in the teachers' expectations led to better performance on the part of the students.

Rosenthal and Jacobsen (1992) elaborated on their finding that children who are expected to do perform better by their teachers typically do so. Although they could not find that the teachers had spent more time with the children who were labeled as a 'bloomer,' they believed that it was the importance of the interaction between the teacher and the student that made the difference.

Karakowsky, DeGama, and McBey (2012) further asserted that while the Pygmalion effect leads to higher subordinate performance, it also includes an element of vulnerability. The subordinate must be willing to take a risk and interact with the leader. Therefore, there must be a certain level of trust in the leader for there to be a positive impact on the subordinate. 


\section{Conceptual framework}

Much of the existing research regarding tracking utilized Oakes' theory of tracking as the conceptual framework and employed a qualitative methodology to study tracking. The research emphasized that teachers in the United States have a great deal of input regarding what courses students are placed into. However, they base these decisions on poorly defined policies rather than examining academic performance. Additionally, the research indicates a sense of futility amongst the students in lower tracks. Many students feel they have been identified as 'dumb' and that there is no reason to try to improve their academic performance. Furthermore, the research establishes a pattern of lowered teacher expectations and a relationship exists between the lowered expectations and low student achievement.

However, for purposes of this study, critical pedagogy and interest-convergence will be employed as the conceptual framework. Although Freire based his observations on critical pedagogy from his time in Brazil, the message is transferable to education practices here in the United States. Freire (2000) emphasizes that dehumanization stops people from becoming more fully human. In the struggle for humanization, the oppressed struggle against those who dehumanized them. Their job becomes to not only liberate themselves, but to restore the humanity of their oppressors as well. Freire asserts that only power that comes from the oppressed is strong enough to free both groups. The oppressed individuals must see their oppression as a limiting situation that can be transformed. The pedagogy of the oppressed has two stages; the first is to unveil the oppression and commit to the transformation. The second is when the pedagogy belongs to all of the people involved in the process. 
Freire (2000) points out that authentic education is not carried on by the teacher for the student. Instead, it is conducted by the teacher with the student and is impacted by the world which challenges both participants. The objective is for both participants to be transformed together. Oppressors are those who try to indoctrinate people and adjust them to a reality that is to remain unchanged. Educators often indoctrinate students into the world of oppression without even realizing it. Freire reminds people that it is not their role to speak to others about their own views of the world, but to engage in dialogue with people about their views and our own. Oftentimes, educators are not understood by the people they speak to which causes further alienation. Freire asserts that human activity is theory, practice, reflection, and action. Therefore, people have a fundamental role in the transformation process. Oppressors find their authority by ruling over their subordinates; revolutionaries who wish to lead must be reborn and work with the oppressed.

Critical pedagogy is a philosophy of education that insists that social justice and democracy not be separated from teaching and learning. Instead, its goal is to emancipate people from the oppression and to affect change through political action and social critique. Freire goes on to emphasize that the majority of teacher-student relationships involves the teacher speaking to the students about reality as if it is predictable and motionless. This does not cause a transformation, rather it is simple memorization of facts. Essentially, students are depositories for information. Once students start to become more critically conscious and are posed with problems that relate to themselves and the world, they will feel challenged and respond accordingly. Their responses to 
these challenges evoke new understandings and the students become committed to the process (Freire, 2000).

Shor (2009) underlines these assertions by Freire by emphasizing the fact that it is easy to be a bad teacher but difficult to be a good one, no matter what kind of pedagogy the teacher practices. He examines grading practices in schools and points out that strong relationships and democratic practices in classrooms matter even more because they offer the opportunity to develop a free and just society, thus going beyond the grading practices the teacher employs. Shor offers students the tools to contest his grading of their writing and the opportunity to revise their work for a higher grade. This participatory process is a central tenet of democracy and education. Dimick (2016) provides an example of how a teachers' practice can impact students. She studied the potential critical pedagogy had in three urban high school science classrooms, one of which was an Advanced Placement course. In these classes, the teacher led discussions about park restoration activities rather than just give a simple assignment. These discussions helped to increase the students' engagement in critical consciousness, a crucial component of critical pedagogy.

However, critical pedagogy has evolved over time. Tarlau (2014) asserts that critical pedagogy has become disconnected from its basis in political organizing. Instead, researchers are using critical pedagogy to critique schools but failing to look at how teachers using critical pedagogy can link to larger movements to promote social transformation. She argues that the understanding of the relationship between education and social change needs to be deepened. Tarlau (2014) continues this point by 
emphasizing that critical pedagogy researchers often fail to make the connection between educational practices and real examples of social change.

Issues surrounding critical pedagogy and education are not limited to the traditional school system. Castro and Brawn (2017) point out that the United States incarcerates more people than any other country in the world; therefore, their education should be studied. They emphasize that critical approaches to teaching and learning are difficult within prison classrooms due to the controls that are in place and the authoritarian management style. Critical pedagogy aims to free thought and action from constraints such as poverty, capitalism, and white supremacy. Pushing people towards critical consciousness, a vital component of critical pedagogy, is difficult, even if the people are not in prison.

Critical pedagogy has a basis of more than just its impact on the classroom setting. Ford (2014) asserts that critical pedagogy is tied to identity politics due to the fact that oppression often occurs along the lines of identity, which helps to solidify identity categories which can result in exclusion. While he points out that critical pedagogy is a means to combat oppression and inequality, it does not cause liberation. Ford (2014) argues that critical pedagogy needs to ask how it can serve and show respect for the ineffable, that is for what cannot be represented. Grenier (2016) goes further and sees critical pedagogy and reflexivity as having reinforcing agendas. He views reflexivity as "presenting an opportunity to develop transformative forms of teaching and learning practices" (p. 155). He believes that a reflexive approach to teaching can make contributions to critical pedagogy objectives. By building students' awareness of diverse premises, students can gain a critical understanding of theory versus 
practice. This contributes to critical pedagogy by encouraging students to question the knowledge they had previously taken for granted and to direct their focus towards the complex interactions of people. It also creates greater self-awareness among the students and helps to open up the knowledge sharing process in the classroom.

The point of critical pedagogy is to create an awakening that initiates changes that promote social justice. Hantzopoulos (2015) points out that schools are either the gateway for advancement or a way to maintain the status quo. Despite efforts to change things, schools still utilize a hidden curriculum that perpetuates the current social and political order. While schools may be the site of democracy and social transformations, they can still limit people and stop change from occurring, even when positive change is intended. Despite these limitations, Hantzopoulos still views schools as a site where collective struggles can be self-reflecting and evolving, thus helping people to grow. Students must be involved in a participatory education which allows teachers to be responsive to the students as they bridge the realities of their education and the world around them.

Willink (2008) underscores that pedagogy is presented as being color blind. However, white pedagogy dominates most schools. This form of pedagogy reinforces systems of advantage and disadvantage. It ensures that inequality becomes a natural outcome for those are deemed deficient; therefore, the school system is absolved of any responsibility. This creates two problems; it rewards capitalism and it creates citizens that the school determines are "good" (p. 70). This type of system calls for the implementation of critical pedagogy in schools so that students have an equal opportunity to receive a quality education. 
Although Freire's work is considered one of the fundamental pieces for understanding critical pedagogy, it is not without its critics. Lotier (2017) emphasizes that these are dire times for critical pedagogy as it pushes for freedom, dignity, and generosity while avoiding exploitation. He asserts that while many researchers sympathize with the progressivism that critical pedagogy promotes, many have concerns about it ethically. They are afraid it may reproduce the authoritarianism that it argues against in the first place. He calls into question Freire's work because Freire was interested in the workings of power while promoting emancipation. He argues that students and teachers should work for freedom differently because if teachers knew how to fix complex problems, no one would need to teach students to resist the educational process. This thought process, however, can be challenged by one of the major points of Freire's work which emphasizes the importance of dialogue between teachers and students. Freire points out that dialogue is an encounter between people than can transform the world (Freire, 2000).

Bell's (1980) work over interest-convergence is also an important tool to use to study the impact that tracking has on a school system. Bell reviewed the Brown vs. the Board of Education decision and found that there was no conflict of interest between whites to not associate with Blacks and vice versa. He contends that the Brown decision was inevitable because it positively impacted both groups, including from a financial standpoint.

\section{Summary}

Current research clearly indicates that tracking is detrimental to students both in the United States and abroad. Teachers as a whole have lowered expectations regarding 
students in lower tracks and there is a sense of futility amongst the students placed in the lower tracks. The school system will need to thoroughly study this information as it emphasizes a pattern of how tracking can be harmful and how teachers' perceptions of students in course placement impacts their instruction and the students' academic achievement. Utilizing critical pedagogy and interest-convergence as the conceptual framework will allow for careful study and analysis of practices to determine if current curricular and placement decisions are being made that promote social justice. If the district does consider doing away with the tracking system or making modifications to the existing structure, this literature review will be a crucial element in supporting their assertions about the ways the current system is impacting the students and the education they receive. 


\section{References}

Ansalone, G. (2010). Tracking: Educational differentiation or defective strategy. Educational Research Quarterly, 34(2) 3-17.

Ansalone, G., \& Biafora, F. (2004). Elementary school teachers' perceptions and attitudes to the educational structure of tracking. Education, 125(2), 249-258.

Archbald, D., \& Keleher, J. (2008). Measuring conditions and consequences of tracking in the high school curriculum. American Secondary Education, 36(2), 26-42.

Baoyan, Y., \& Minggang, W. (2015). Changes in urban-rural social structure and distribution of high school educational opportunities — an analysis based on middle school graduation education tracking in Q County, Gansu. Chinese Education \& Society, 48(6), 433-452. doi: 10.1080/10611932.2015.1119509

Bell, D. A. (1980). Brown v. board of education and the interest-convergence dilemma. The Harvard Law Review, 93(3), 518-533. doi: 10.2307/1340546

Bernhardt, P. E. (2014). Making decisions about academic trajectories: A qualitative study of teachers' course recommendation practices. American Secondary Education, 42(2), 33-50.

Castro, E. L. \& Brawn, M. (2017). Critiquing critical pedagogies inside the prison classroom: A dialogue between student and teacher. Harvard Educational Review, 87(1), 99-121.

DESE (2016). Missouri district and school information. Retrieved from https://mcds.dese.mo.gov/quickfacts/Pages/District-and-School-Information.aspx DESE (2016). Missouri learning standards. Retrieved from 
https://dese.mo.gov/college-career-readiness/curriculum/Missouri-learning-

standards

DESE (2016). Missouri school directory. Retrieved from

https://mcds.dese.mo.gov/guidedinquiry/District\%20and\%20School\%20Informati on/Missouri\%20School\%20Directory.aspx

DESE. (2016). Top ten by twenty. Retrieved from https://dese.mo.gov/top-10-by-20

Dimick, A. S. (2016). Exploring the potential and complexity of a critical pedagogy of place in urban science education. Science Education, 100(5), 814-836. doi:

$10.1002 /$ sce. 21233

Ford, D. R. (2014). A critical pedagogy of ineffability: Identity, education and the secret life of whatever. Educational Philosophy and Theory, 46(4), 380-392. doi:10.1080/00131857.2013.779218

Freire, P. (2000). Pedagogy of the oppressed. (M. Bergman-Ramos, Trans.). New York, NY: Continuum. (Original work published 1970)

Grenier, F. (2016). How can reflexivity inform critical pedagogies? Insights from the theory versus practice debate. International Studies Perspectives, 17(2), 154-172. doi: 10.1093/isp/ekv006

Hantzopoulos, M. (2015). Sites of liberation or sites of despair? The challenges and possibilities of democratic education in an urban public school in New York City. Anthropology and Education Quarterly, 46(4), 345-362. doi:10.1111/aeq.12115

Karakowsky, L., DeGama, N., \& McBey, K. (2012). Facilitating the Pygmalion effect: The overlooked role of the subordinate perceptions of the leader. Journal of Occupational and Organizational Psychology, 85, 579-599. 
Karlson, K. B. (2015). Expectations on track? High school tracking and adolescent educational expectations. Social Forces, 94(1), 115-141. doi:10.1093/sf/sov006

Kelly, S. (2007). The contours of tracking in North Carolina. The High School Journal, 90(4), 15-31.

Kelly, S., \& Carbonaro, W. (2012). Curriculum tracking and teacher expectations: Evidence from discrepant course taking models. Social Psychology of Education, 15(3), 271-294.doi: 10.1007/s11218-012-9182-6

Lotier, K. M. (2017). On not following Freire: Foucault and the critique of human capital. Pedagogy, 17(2), 151-175.

Marzano, R. J. (2003). What works in schools: Translating research into action (1st ed.). Alexandria, VA: ASCD.

Modica, M. (2015). My skin color stops me from leading: Tracking, identity, and student dynamics in a racially mixed school. International Journal of Multicultural Education, 17(3), 76-90.

Morris, E. W. (2005). From middle class to trailer trash: Teachers' perceptions of white students in a predominately minority school. Sociology of Education, 78(2), 99121.

Northouse, P. E. (2016) Leadership Theory and Practice. (7th ed.) Los Angeles, CA: SAGE.

Page, R. (1987). Teachers perceptions of students: A link between classrooms, school cultures, and the social order. Anthropology \& Education Quarterly, 18(2), 77-99.

Rosenthal, R. \& Jacobson, L. (1992). Pygmalion in the classroom: Teacher expectation and Pupils' intellectual development. Williston, VT: Crown House Publishing 
Limited. (Original work published 1968)

Shor, I. (2009). Critical pedagogy is too big to fail. Journal of Basic Writing, 28(2), 6-27.

Tarlau, R. (2014). From a language to a theory of resistance: Critical pedagogy, the limits of "framing," and social change. Educational Theory, 64(4), 369-392.

Van Houtte, M., Demanet, J., \& Stevens, P. A. (2013). Curriculum tracking and teacher evaluations of individual students: Selection, adjustment or labeling? Social Psychology of Education, 16(3), 329-352. doi: 10.1007/s11218-013-9216-8

Van Houtte, M., \& Stevens, P. A. (2015). Tracking and sense of futility: The impact of between-school tracking in secondary education in Flanders. British Educational Research Association, 41(5), 782-800.

Willink, K. (2008). Economy and pedagogy: Laboring to learn in Camden County, North Carolina. Communication and Critical/Cultural Studies, 5(1), 64-86. doi: $.1080 / 14791420701821781$ 


\section{SECTION FOUR:}

CONTRIBUTION TO PRACTICE 


\section{Contribution to Practice}

\section{Introduction}

Tracking, the method of sorting students into classes based on predetermined mechanisms has been found to be detrimental to students. The system of sorting students in the southeast Midwestern school has been in place for over sixty years; it begins at the junior high level and has the stated goal of helping to provide differentiation for students. The school district itself is rich in tradition. It has been in existence since the early 1900s and enjoys a great deal of support from the community in regards to athletics and competitions where the school performs well. However, there are concerns about the effectiveness of the tracking system as well as the individual teacher's perceptions. The Midwestern Department of Elementary and Secondary Education (DESE) launched the Top Ten by Twenty initiative which is an effort to improve Midwestern student

achievement into the top twenty in the nation by 2020. A large part of this endeavor is to ensure that all students are college and career ready (DESE, 2016).

\section{Literature Review}

A great deal of research exists that shows students are assigned to classes based on what others believe is their academic ability. Tracking leads to unequal access to educational resources and different treatment of students (Ansalone, 2010). He goes on to assert that there is little support for the idea that tracking students improved their academic achievement. Additionally, he found that those students in higher-tracks are often presented the curriculum in a better way and have higher expectations from their teachers. Ansalone and Biafora (2004) went further and emphasized that the research showed that children from lower socioeconomic families are more likely to be held back 
in school and not complete their education. Page (1987) found in lower and regular track classes that the curriculum differentiation was not equitable to the students' interests. Those students in lower track classes receive a basic education while those in higher track classes get additional opportunities.

Additionally, the idea of student-teacher relationships is also an important factor to consider when examining the impacts of tracking. Kelly and Carbonaro (2012) found that teachers in higher track classes had higher expectations than teachers in lower track classrooms. Those teachers believed that students in higher track classes considered themselves to be college bound and they molded their instruction accordingly. Those in low track classrooms found students to be disruptive and inattentive.

The idea of the impact of students' socioeconomic status has also been studied in regards to tracking. Rosenthal and Jacobsen (1992) found that teachers believe that students from middle class families do well in school while those from lower classes have difficulties. They tested this idea in a school where teachers were given a list of twenty percent of their students and told the students were about to excel. They were not allowed to discuss this information with the children or their parents. The differences between the children that had been marked for growth and the control group showed that teachers can be responsible for students' gains. They referred to this as the Pygmalion effect where an increase in expectations led to better performance.

\section{Conceptual Framework}

There was a gap in the literature concerning how course placement impacted teachers' expectations and perceptions of the students in their classrooms, as well as whether they had lower expectations of the students placed in the lower level 
courses. Additionally, a gap existed in regards to what instructional strategies were utilized in the different tracks. Prior research primarily utilized Oakes' theory of tracking as the conceptual framework. This framework suggests that there are disparities in education due to placing students in various tracks. Therefore, some students receive a higher caliber of education than their peers (Ansalone \& Biafora, 2004; Bernhardt, 2014; Kelly, 2007; Modica, 2015; Page, 1987). This study was conducted using critical pedagogy and interest-convergence as the conceptual framework. Critical pedagogy questions how power structures manipulate rationality and truth. It calls on educators to transform education, give students opportunities, and promote democratic ideals (Foley, Morris, Gounari, \& Agostinone-Wilson, 2015). Freire asserts that critical pedagogy is crucial when educators are working with an oppressed population because being liberated from oppression is not a gift or an act of self-achievement, instead, it is a combination of the two factors (Freire, 2000).

Bell's (1980) theory of interest-convergence examines the impact that Brown vs. the Board of Education decision had on the population. His theory argued that there was no conflict of interest between the rights of whites not to associate with Blacks and vice versa. He contends that the Brown decision was inevitable and that the monetary impact was the reason for integration to occur.

\section{Purpose of the Study and Emerging Themes}

The purpose of this study was to examine the impact that various instructional strategies and approaches have on achievement, how course placement affects instructional behavior and course approaches, and to determine what types of instructional practices are being utilized in classroom instruction for both grade-level and 
college preparatory class and if they differed or are equitable. In analyzing the data from the interviews, focus groups, and classroom observations, several themes emerged. These included differences in instructional strategies that are utilized in a college preparatory class and not in a grade-level course. Lower academic achievement in gradelevel courses and a stigma that is associated with placement in grade-level courses also emerged. Teachers also noted differences in classroom management styles in the two types of courses. Maturity level, motivation, and the need for more positive role models in a grade-level course were all areas of concern. Additionally, all participants stated a desire to have the students blended rather than separated into the two types of courses.

\section{Differences in Instructional Strategies}

The teachers in the school district showed an obvious commitment to educating their students but quickly acknowledged that having grade-level and college preparatory classes leads them to utilize different instructional strategies. One junior high teacher stated in regards to her grade-level courses, "I might go a bit slower or use some different material. We have A and B reading study guides. A version is supposed to be a bit easier." She further elaborated by saying, "I definitely try to push my grade-level classes. I try not to dummy down the work, so to say. I try to give them the same material. I might present it different or explain it a little better or do a different kind of note-taking strategy than I might with college prep, who might just get it from my saying it. Whereas, a grade-level may not get it unless I explain it differently or we do some type of activity to back that concept up."

These thoughts were apparent in the classrooms where the researcher did observations and scripted what was occurring. Hattie (2012) analyzed the effect size of 
various instructional strategies on learning and found strategies with a high effect size had a positive impact on achievement. Instructional strategies with a low effect size did not have a helpful effect on achievement. One observation in a grade-level science class quickly illustrated the points made by teachers in the interviews and focus groups. The class began with a lot of idle chit chat while the teacher instructed the students to get busy on the bell ringer. The teacher gave frequent reminders to the class to get quiet and work. A new student was present in the class and the teacher explained the procedures for keeping a notebook in the class. The teacher told the student, "Don't use these guys as an example," and pointed to other students sitting near the new student. The teacher began showing a video over weather and the atmosphere and instructed the class to write down fifteen facts about the video in their composition books. He stopped the video at various points and made statements about how things mentioned would be good ideas to write down in the composition book. There was no usage of questions involving deeper levels of thinking. It was direct instruction and the teacher told the students what to write. Throughout the video, many students put their heads down and stayed that way until the teacher went around and told them to sit back up and work.

In an English grade-level class, the objectives were clearly stated on the board. The class was going to discuss dangling modifiers, complete a brief assessment over dangling modifiers, and choose an independent reading assignment and begin reading the passage. The students began working on an activity regarding the dangling modifiers while the teacher walked around and inspected progress. She began asking the students to define some terminology from the assignment. This led to other questions about the assignment where the teacher would ask a question, a student would respond, 
and the teacher would correct the response. All of the questions were low level questions and only required simple recall. The teacher asked the students, "What is the dangling modifier in this sentence," but did not elaborate by asking how the sentence could be improved. There was a lengthy discussion of what dangling modifiers were and the class practiced an assignment out of the book. Only one higher level question was asked when the teacher asked what the students thought would be a way to change a verb to a different form. The class then selected their reading passages and read silently.

Very little higher-level thinking was present in a grade-level math class. This aligned with Ansalone's (2010) work where he found that those students in higher-track classes are often presented the curriculum in a different way. The class was instructed to get to work on their independent assignments that were available online. The teacher stated that the class was going to begin learning about two-step equations that day. Students slowly started coming up to the teacher individually for help on the assignment. After a couple of students had come up and asked questions, the teacher asked the class what coefficients were. Then, after the student responded, the teacher corrected the behavior of the class and asked a student if she was working. Directions became highly instructive and the teacher told the students to put their earbuds away and to put their names on the assignment as soon as they received a copy of it. A group of young ladies was not paying attention and the teacher asked them if they were ready. Then, the teacher gave instructions about two-step equations and did not ask many questions regarding why the equations worked the way they did. The instruction was very traditional where the teacher did the talking and the students took notes. This 
observation supported Hattie's (2012) research which emphasizes that tracking has an effect size of .12 which is very low in impacting academic achievement.

The theme of the teacher having to constantly be concerned with discipline was also apparent in another grade-level science classroom. Ansalone and Biafora (2004) asserted that teachers leading lower-track classes were often more concerned with classroom management issues. In this observation, the teacher began the lesson and told the students not to talk; she also glared at a student who was attempting to speak to a friend. She began returning papers and speaking to students as she did so telling one student, "You need to sit back here. Just because your Ipad's dead doesn't mean you can change seats." She then told another student, "This is not a good time to be on your Ipad right now." She passed out a paper and had the students write their names at the top. She then had them trade the paper with their seatmate. They were instructed to write down traits about the person on the worksheet. This was one example of a teacher utilizing some group work in a grade-level class. This lasted for a total of seven minutes. The students were then instructed, "Go step-by-step on this next part. Put your pencil down. Please do not work ahead. Stay with me." She then asked a student to define what a phenotype was. After the student defined the term, she stated, "Look at your paper. Write that description in that column." The instructions throughout the lesson continued to be highly guided the entire class period. She then asked the class to vote on how they wanted to read the lesson; after some discussion, they voted that they wanted the teacher to read the selection aloud to them. The teacher passed out a study guide that accompanied the reading selection and began reading the passage. She would stop each time they covered the answer to a question. She told them to write the answer down and 
walked around the room to see that they did so. After she completed reading the selection, she started going around to individual students, inspecting their work, and helping them get organized. This included going through their class folder and putting the work in order. She gave frequent reminders to students to behave and stay on task.

The college preparatory classes were quite different from the grade-levels ones. Page (1987) emphasized that higher track classes often can participate in a variety of activities and experiences. This was apparent in all the college preparatory class observations. There was an immediate impression of the teacher offering less direction and not making frequent reminders about behavior. One English teacher was conducting a jigsaw assignment. Each student was assigned a question about global warming and had researched facts about their question. They prepared a presentation on their Ipads about their question and shared their findings with their teammates. The students were allowed and encouraged to talk to one another while the teacher walked around listening to the conversations. Additionally, the teacher went over the state standards that applied to the lesson, including speaking and listening. The teacher reminded the class that they were not only being assessed on the material they presented but how they presented it. She went on to state that the students would evaluate one another as well. As the presentations continued, the teacher reminded the class to make sure they cited their material. The teacher then instructed the students to write down something they had learned on piece of paper and to be specific in their answers. The class then shared out their findings from the notes. Finally, the teacher asked the class for feedback on the activity regarding what they liked, what could be done differently, and if they found that they were able to learn more by working with a group of people rather than as 
individuals. Hattie (2012) found that giving and asking students for feedback had an effect size of .75 and has a high impact on learning. Additionally, the teacher had gone over her expectations for the students which has an effect size of 1.44 .

It was also apparent in a college preparatory social studies class that the students and teacher were engaged at a higher level of thinking and interaction. The teacher began a presentation over Islam and asked the students questions that not only required simple recall but also that they connect the learning from the current unit with previous units. Connections were also made to artwork, movies, and other forms of media. The teacher passed out a graphic organizer and had the students begin filling it in while she walked around the room inspecting progress and helping. When students would pose questions to her about the culture, the teacher often responded by asking, "What do you know about that?" rather than simply answering. This led to other students getting involved in the discussion and more interaction.

A college preparatory Algebra I class was also highly engaged. There was a great deal of interaction between the students and the teacher. The teacher began by asking the students to put their Ipads away so they could review for a quiz. She began writing a problem on the board and asked the students what the first step was that needed to be completed to solve the problem. They also discussed terminology in the questions and what it meant regarding the required answer. As the students began working on the quiz, the teacher walked around the room inspecting their work and offering assistance. She did not give them the answers to the problems. She asked probing questions that helped to inspire each student's thought process. She gave frequent encouragement and made supportive statements to the entire class throughout the whole class period. The use of 
problem-solving that was being employed in this room had an effect size of .61 which has a high impact on academic achievement (Hattie, 2012).

It was also obvious in another college preparatory social studies classroom that the students were expected to perform at a higher level than in a grade-level classroom. The students were instructed to pull out the guided reading activity and began going through it. Instead of just answering the questions, the teacher made the students justify their answers. The teacher frequently said, "Tell me why," or, "Don't just say true or false." She laughed with the students about funny statements and made sure to call on students who were not participating as actively in the discussion. She utilized good use of wait time to get more students to respond to her questions and showed the students how the lesson applied to the boundary between the United States and Canada today.

The same commitment to educating the students was apparent at the high school level as well where a teacher stated, "In teaching a grade-level class, we don't focus on the same level of skill as reading level. For example, this year we taught three different novels for grade-level, college preparatory, and honors. We would approach the same skillset, but at different reading levels. And we wouldn't approach the novels with the same time constraints. We would move much slower with the grade-level than the college preparatory. The grade-level would be doing a lot of whole class learning. Independent at college preparatory." When asked about the ways she differentiated her instruction in grade-level and college preparatory classes, the teacher emphasized, "Grade-level, when we're focusing on the writing skills and that type of thing, we don't require as lengthy, as detailed, as in-depth writing, as we would the upper level classes. They are going to have to have more of the advanced skills in their writing in order to 
accomplish a score of proficient or advanced. Whereas you wouldn't expect, I hate to say it that way, you wouldn't expect the grade-level to even get advanced." She elaborated by saying that there was a difference in the way the two classes write, “Typically with the grade-level class you're going to have to give them a formulaic prescriptive essay: five sentences, five paragraphs. When you get to, and let's just say we're doing an argumentative [essay], you'd give a very prescriptive argumentative essay to the grade-level, probably even guide them on their thesis. Basically, a fill in the blank type activity. Whereas you're going to allow for more creativity when the college preparatory and the AP or honors." This teacher, like those at the junior high, also noted a difference in how students take notes in the two courses, "Notes are a lot slower in grade-level classes. College preparatory, I tend to give a small upfront, but I think when it goes to direct instruction with the grade-level, it's a hold your hand all the way through the lesson. You got to give it to them in little pieces and not overload them at the beginning."

A teacher with over twenty year's experience who had also been a student in the school system noted the differences in instructional strategies by saying, "I do have to slow down with my grade-level. I do different types of stuff on the bell ringer. I once put them in groups, that was a bad idea because like I said I literally have two children that should be in college prep. I have about four or five out of twenty-two that it's the same five with their hand in the air." She went on to state that with college preparatory she can do share-pair and comparing answers and is unable to do that with grade-level because she would lose them. 
A junior high math teacher who participated in a focus group and has experience in another school district noted that with her grade-level classes, "The amount and depth of the information is decreased. I feel like I have to just skim with grade-level, especially with math. My grade-levels require so much more practice, so many more problems and we just can't go quite as deep in those classes." Another participant in the focus group concurred with this statement and added, "I have to give multiple examples for gradelevel, whereas for college prep, I tell them how to do it and it's like they already have an idea of what's going on."

The focus group went on to emphasize that grade-level classes must be given the information directly. One said, "You have to physically feed them the information, what they need to know, because they are not, they don't have the wherewithal yet, to make a decision on their own and do a little bit of self-searching, self-investigating." Another responded that college preparatory classes want to learn but grade-level asks the teacher what the answer is and what they need to write down on their papers.

The second focus group emphasized they modify their instruction and assignments for their grade-level classes. One said, "I will try to give more support, I guess you could say. When they do the guided reading, I'm more helpful with them. Helping them learn how to look in the book for the answers, that kind of stuff. On quizzes, I modify the quizzes. So that they don't have the same type.” They also stated that they are unable to do group work in grade-level classes due to behavioral issues. Another participant said, "If we do say, a guided reading type activity, basically, we're going to have to read the text together. We're going to have to read the question together. We're going to have to diagnose that question together to figure out where we 
can find the answer. But with the college prep, you can say, “"Okay, I'm going to give you ten minutes to read over this section and answer these questions. And then we're going to go over it." Another one stated, "With grade-level, we'll do it together. Like, I will go through it, and we'll find the answers together." This statement was supported by another participant who said if the answer is not exactly the same as the wording on the assignment, the students will say they don't know how to do it.

Participants in the second focus group went on to give examples of how they utilize direct instruction more in their grade-level class than their college preparatory. One stated, "With my grade-level, I will tell them what I want them to know. I don't give them an opportunity to think it through or explore it sometimes because their thought process is totally off track. And I do know, if they hear it wrong or learn it wrong, it's going to stick." Another responded, "So, with grade-level, I'm going to be more telling them the answer."

The idea of having a commitment to educating all the students was also apparent in a first-year high school teacher. He stated, “They're all fourteen, fifteen-year-old kids. They're all here because they have to be. But they're all here for some sort of an education. I feel that as teachers we don't do our best job if we don't treat the lowest kids like the highest kids." Despite this belief, he went on to state that there are differences in the instructional strategies that he implements in his classes. He pointed out that his grade-level classes follow the actual textbook more while college preparatory has more projects. The idea of having more projects for college preparatory classes was also conveyed during the second focus group. One participant stated, "I can use more of a 
variety of instruction because they can handle it, group work, just different ways to get the content to them."

\section{Lower Academic Achievement}

A consistent theme emerged from all participants stating that academic achievement is lower in the grade-level courses than in college preparatory. One teacher emphasized, "My grade-level classes are not successful. [The] majority of them are failing. As a whole class, generally they are doing very poorly. Now, in college prep classes, the majority of them are doing great." The first-year high school teacher stated, "I tend to see lower grades in my grade-level classes. I have a bunch of people that are failing."

Participants in the first focus group emphasized the difference in academic achievement by pointing out that in a college preparatory class if they pose a discussion question, someone will have a comment about it while students in grade-level classes will just stare at them. The second focus group pointed out that they have lower grades in their grade-level classes and that it is mostly due to missing work. One said, "I can sit and give them a piece of paper with five questions and I can go through every single answer on the paper and give it to them word for word. Repeat it twenty times, and they just won't write it down." This point was emphasized by all the participants in the second focus group. One person said, "And I tell them, 'I do this genuinely just for you to boost your grade. If you got a bad grade on the test, here's this.' And we do it every Friday, and every Friday, my seventh hour and my second hour, I'll get, maybe, three or four of them done." 
One participant also noted the impact on achievement when a student was moved from her college preparatory class to a grade-level one. She emphasized, "The counselor told me that the student's mother wanted her moved to grade-level. I was confident that she could handle the work in college preparatory and that is where she needed to be. She had already completed assignments for me and was doing very well. The counselor said she didn't have a choice; the student's mother wanted her moved, so she made the change. I saw a change in the student right away. She began to act out in class, not complete assignments, and the overall quality of her work was not as good as it had been prior to her being moved. I've even had students tell me when they've been moved from college preparatory to grade-level that the reason their grade drops is that they can't appear to be smart in front of their peers."

\section{Stigma in Grade-Level Courses}

One theme that was not as apparent as others but came through in some of the interviews and focus groups was a stigma that is associated with being in a grade-level class. Freire (2000) asserts that dehumanization stops people from becoming fully human. As people struggle to become human, the oppressed person struggles against those who dehumanized them. He goes on to state that only power that comes from the oppressed is strong enough to free both groups. This assertion was supported by statements from participants regarding the stigma that students have from being placed in grade-level classes. The first-year high school teacher said, "Honestly, I think that it comes from where there is a stigma attached to grade-level. It's 'I'm at grade-level, I'm not as smart as everybody else. I don't know how to do this work, it doesn't matter."' He elaborated and said that there is a perception amongst the students in grade-level 
courses that they are there because they are not smart enough. These assertions were supported by Karlson (2015) who found that students perceive the tracking system as a sign of their abilities, and they respond to it by adjusting their own expectations. The results from her work found that students tended to base their own expectations of themselves on their track placements. She found that this leads to social labeling about each student's abilities.

One participant summed up the feelings of the entire group by stating, "They think they're dumb." This statement was almost repeated in the second focus group when a participant stated that she has had students in grade-level courses tell her, "Well, I am dumb. I can't do this. I'm in grade-level." Another participant in the first focus group also stated, "I think they know they're labeled for sure. I mean, whether or not it's meant to be derogatory or not, they take it that way. Oh, they're in the smart class. Or, we're just in the whatever class."

One member of the first focus group discussed the stigma that is associated with being in a grade-level class with how students have responded when she has had them moved to a college preparatory class. "The ones that I've moved, every kid in three years that I've moved, it has been like you just give them a thousand dollars when you said, 'I think you really probably should move to college, to college preparatory classes. I think you can handle it.' It's like you just told them something no one's ever told them before. It's like their whole world changed." This was also reiterated by a participant in the second focus group who had a student moved from a grade-level class to a college preparatory class. She said that the student was capable of doing the work and that his behavior improved after changing his schedule. She said, "He's changed from seventh 
hour grade-level to first hour college preparatory. Work is getting turned in. He's putting his headphones in, and he's getting down and doing his work, getting done before anyone else. He is kind which he used to never be. We used to not get along. He comes now, and he's done his work. He sits by my desk and we'll talk. And actually talk to him. Like, he has, it's like, pulled him out of a funk. And he feels better. Like, his selfesteem is up, almost."

Another participant in the second focus group emphasized, “They're grouped in with the kids with the behavior problems. And so just all together just kind of brings them in the mood and their progress down." Another responded to this by saying, "Well, their class is actually named differently. You're in grade-level. And you're in college preparatory. You know, it's automatically a stigma on them."

The second focus group stated that separating the students into grade-level and college preparatory classes makes a clear division and the students are aware of it. One participant said, "It's like the kids that are in grade-level, I think they start to get this idea in their head, that they are bad kids. Because they are constantly grouped with the bad kids, in their mind. It's like a lot of the kids that are in those grade-level classes, almost get that idea about themselves, 'Well, oh, I'm a bad kid. Oh, I'm this or that'. And they just kind of follow that trend or behavior." Another participant said that the grouping of students into grade-level and college preparatory classes causes the school to "segregate your population."

A veteran teacher who attended the Springville school district noted the impact as well that moving from a college preparatory class to a grade-level class can have on a student. She noted, "I was in college preparatory history. I didn't do well on a test. The 
next thing I knew, the teacher gave me a slip that said I had been moved to a grade-level class. I was mortified. None of my friends were in the class. I didn't know anybody. I struggled that year. I kept my head down. When my friends saw me going into the room, they asked me why I was in that class. I was so upset that I didn't learn anything that year in that class."

Participants in the second focus group also stated that they continually must remind their grade-level classes that they are capable of doing the work but have to contend with the students being down on themselves. They emphasized that this is a continual struggle and that many of the students display a defeatist attitude, even though they remind them that they are fully capable of doing the work.

\section{Differences in Classroom Management}

Kelly and Carbonaro's (2012) assertions that teachers in lower track classes found students to be disruptive and inattentive were apparent in the interviews and focus groups. The participants emphasized that they must maintain stricter control in their grade-level classes as compared to their college preparatory ones. One teacher stated that it, “...takes away from those who are truly grade-level and truly need some extra help because I'm dealing with the ones who don't want to behave, that just want to goof off, and whatever. My grade-level classes completely wear me out. I'm completely exhausted. I have to watch their every move. I have to be up and at it constantly. I cannot trust them to work independently. I have to basically constantly monitor what's going on. Whereas my college prep classes, I don't worry about them so much. I mean, they're responsible, and they get to work and they do what they're supposed to do. Yes, I 
walk around the room, and yes, I check on them, but not as intensely as I would with my grade-level class."

High school teachers also pointed out a need for a stricter classroom management system in their grade-level courses. One stated, "I'm thumbs on, no room to breathe with the grade-level kids because they tend to be your students that act up. College preparatory gets a little more freedom to a do a little more if college preparatory's proven to make that they're going to do their work and they're going to work quietly and effectively. I might allow them for example with their Ipads, put in your earbuds, do your work."

A junior high math teacher pointed out, "It's just more of a stay on top of gradelevel and looking around behavior management, all of that, and college prep I can kind of give them more leeway with it."

Even first-year teachers noted that they employ a stricter classroom management style in their grade-level classes compared to their college preparatory ones. One stated, "I've learned with the first couple of days that I have to teach bell to bell. That downtime is potentially bad. I'm more lax with my college prep kids." He went on to note that having a routine is crucial in grade-level classes to help keep his classroom under control.

One second-year junior high teacher noted, "I have to give more structure to my grade-level classes. Whereas, in my college prep classes they can have a little bit more freedom, a little bit more choice, and they can handle it a little bit more."

The first focus group stated that they believe there is an increase in the amount of discipline because the students in grade-level courses often have the same course schedule and spend a great deal of time together. One said, "It's like they travel in packs 
wherever they go. I think those, the grade-levels, tend to get in more trouble and it's more discipline. Those guys tend to travel in groups. They're going to be in his seventh period and my fourth period and whatever. And then they end up in the cafeteria sitting together because they've become friends." This thought was reiterated by participants in the second focus group. One participant said, "Those kids that are doing those things get bundled into a group...But it's hard to teach to those students that really genuinely want to learn because the behavior of the other students is so hard to manage at times." Another emphasized that it is a struggle from bell-to-bell in grade-level classes and that she is continually having to correct students.

The second focus group stated that there is a difference in how students behave in grade-level classes compared to college preparatory classes. One participant said that students in grade-level classes, "Want to talk to each other. Or, they're snickering back and forth with each other." They elaborated by saying that grade-level classes cannot handle freedom.

\section{Maturity Level}

Kelly and Carbonaro (2012) maintained that students in lower-track classes were less engaged in school and had a decreased sense of self-worth. Additionally, they found that teachers rely on social categories to label students. This point was established in a focus group who stated that there was a decreased maturity level in grade-level classes. This theme was first brought out by a math teacher in her second year with the district and twelfth year overall. She asserted that at the junior high level you cannot give the students much freedom, particularly in grade-level classes. "You say everything has to be structured, because if you get off a little bit, you can get off a lot. I think 
organization and maturity level, especially in junior high, is a big issue...It's not necessarily that they can't do the work, it's just the attention span, maturity and staying on task, the just, 'Oh, she means right now. Oh, right now? What'd you say? I forgot.' That's what it feels like with about twenty of them in the class." Another emphasized in regard to grade-level classes, "It's difficult to have a more, like you said, in depth class, because of the maturity levels. You can't change, you can't go on without having to first describe every single bit of what's going on."

They also asserted that the idea of maturity carries over to the organizational level the students have and stated that grade-level students are not as organized as college preparatory students. One stated, "I very rarely give my grade-levels homework, because they don't come back with it. They don't put it in the right spot. They don't do a very good job of keeping a folder or a notebook or a book. They get home and forgot. They just can't come back with it."

The theme of how maturity impacts the instructional strategies that the teachers implement in their classrooms also became apparent in the first focus group. One participant said, "We're supposed to go to a science lab tomorrow and there's no way I could take my grade-level classes because their maturity level is like a two-yearold. You have to treat them like they have no responsibility. I can't give them responsibility." When asked what he did in place of a lab activity, he responded that he does the lab and the students watch.

\section{Motivation}

When questioned as to why students in grade-level classes were not performing as well as those in college preparatory classes, one consistent idea that was pointed out was 
motivation. One participant noted, "I have too many in my grade-level class that have the ability, but do not have the motivation. Their lack of motivation is a constant discipline problem that I have to deal with.” Rosenthal and Jacobson (1992) argued that part of the reason for this type of belief system is that teachers make assumptions about students and often do not realize that their expectations can be responsible for students making academic strides.

Another participant asserted, "Grade-level kids tend not to be motivated to achieve as highly as the college preparatory and the honors kids. Your honors kids tend to be your overachievers and your college preparatory kids tend to be those that they're going to college, but they don't want to do as much work. So, the motivation level is commensurate with the grade-level that they're placed in." When asked what she attributed the difference in motivation to, she stated, "The kids who tend to end up in grade-level classes, they tend not to have a value on education placed upon them outside of school. Whereas the kids that end up college preparatory and honors, their parents tend to be pushing them that way, so there's that value placed on education."

Participants in the first focus group emphasized that they cannot motivate the students, it must come from within. One stated, "I wonder how much of this is, you're going to, again, rise to the level of what's expected of you." Another stated, "I think there's a certain level of intellectual curiosity, too, that has to be a part of their personality, and unfortunately, that's not necessarily something that we can teach. How do you teach someone that you know you need to be curious about the world around you? You can, to a certain extent, but that emotion behind it that drives the intellectual curiosity, you can’t teach people emotion.” 


\section{Need for Role Models}

Bell's (1980) theory of interest-convergence was also apparent in the participants' point that there is a need for role models. Interest-convergence argues that change is not necessarily based on race but rather what is needed to advance a cause because it is advantageous for both populations. The need for role models emerged as a theme when teachers were asked why a problem with motivation existed in the grade-level classes. When one teacher was asked why she believed the students were not motivated, she responded, "Well, in my opinion, being in a grade-level class does not help create a motivational setting. When you have the kids mixed in, college prep with grade-level together in one class, they can see others doing what they're supposed to be doing, and when they're all in the grade-level class, they tend to feed off of one and other, and when one is being goofy, then they all want to be goofy. There's no one to boost morale or to be the leader in a positive way."

A high school teacher noted, "They need to be mixed in, and they need to see the success that the students at the middle of the road and the higher are having, and what motivates them. Because they have no motivation, they don't know what it looks like." This thought was also supported by a first-year high school teacher who asserted, "In college prep, usually in every class there's one or two kids that when you give an essay, they're the ones who get a 95, 96. They're the ones that you can turn to and ask questions to. I think that if those people were in class with people that were grade-level, then we would see better scores from our kids because they have those people around them that are like, 'Hey, you can do this.' They have that hand there that reaches out 
when they need something. I think that we would be able to see those scores from our not as well performing kids come up."

Participants in the first focus group stated that they believe the lack of maturity exhibited in grade-level classes is one reason that students need to have role models. One said, "When you have those organizational issues or you have those behavior issues, there isn't an example in the room to lead, a peer example. So, you have someone swinging from the ceiling, or hanging upside down or whatever. Everybody else is on that same maturity level, so they're now hanging from the ceilings and they're now hanging upside down." One pointed out that when she had a student go from a gradelevel class to a college preparatory class he completely turned around. She said, "He was bad, ridiculously bad. He got in college prep, 180 turn. His grades are starting to improve everything." When she mentioned this, another participant responded that it was probably because the student had a good example in front of him.

The second focus group also noted the improvement in a student who was moved to a college preparatory class. The student had been a continual discipline problem in a grade-level class prior to the move. The teacher stated, "His behavior in seventh hour was atrocious...He doesn't make a peep in first hour because he's surrounded by people who show good behavior...But he's on topic, and he's doing his work, and I have not seen that behavior out of him at all since he moved to college preparatory. Not once. And I think part of it, too, he's sitting in that classroom now, that college preparatory classroom, and that behavior he was exhibiting, if he does that in that classroom while the other kids are like 'What are you doing?' In grade-level, they're like, 'Yeah, that's cool.' College preparatory they're like, 'Dude, stop."' 


\section{Desire to Blend the Classes}

All participants expressed a desire to do away with the system of having gradelevel and college preparatory classes. While they were not aware of all the research that existed that supports doing away with the tracking system, their arguments aligned with Freire's (2000) argument that being liberated from oppression is not a gift or an act of self-achievement, instead it is a combination of the two. One teacher stated regarding the current system, "I don't like it. I think it makes our job a little harder, especially in those grade-level classes. I feel if they were evenly distributed throughout all the classes that we probably wouldn't have such a behavior issue in the grade-level issue. They would be separated out, and they would see kids who are being good, and be discouraged for acting silly." She also made an observation regarding when she has been able to group a lower ability student with a higher one, stating, "I did notice that some of my lower kids, I could group them with one of my higher kids, and they would just really take to him. And my higher kids wanted to take them under their wing, and help them out, and be their little teacher on the side or whatever, so that helped a lot with academic things."

Another teacher noted that blending the classes would enable them to utilize more instructional strategies such as team building, small group lessons, and an increase in desired behaviors. "I think that blending the kids together at the grade-level and college preparatory, I think you would get more of the good behaviors out of the lower kids. I don't think they would behave the same way in front of a group of kids that are intellectually not challenged." When asked if she had ever had a student moved from grade-level to college preparatory and how it went, she responded, "Typically, when you 
move them up, they look at it as an accomplishment or a success and they want to prove to you that they can and it's successful."

The teacher who is a product of the school system noted, "I am used to the whole grade-level, college prep. I was raised that way. I went through school with both of those levels and my first ten years or so teaching I totally agreed with keeping them separate because it was two different books, completely different books. The grade-level book that those children used was a lot easier. It did not take them as far. It still covered the same subjects as the college prep book but did not go quite as far. Not as many word problems or where they had to actually apply. When we started using the same books and I don't remember what year that was it didn't take me but about one school year to realize that we didn't need to separate these children teaching the exact same stuff. We don't need all grade-level in one class and college prep in another and that's when my thinking changed." This thought was echoed by a first-year teacher who also attended the school. He stated, “I don't know if combined I guess is the word I need to use. I'd prefer it if they were just all together. Because I know when I was in class, like I said I was in college prep, AP, I was never top of the class. I was always a smart student. I was always keeping up, but there were people that I could turn to like, 'Hey, I need help with this." This idea was reiterated by a participant in the first focus group who noted that in one instance when she had a low performing student in a college preparatory class, "I always tried to partner him up with student that I knew could help him. What I found from doing that was actually that the other student benefited as well because you learn something the best when you teach it." 
The first focus group also stated that they wished the students were all together rather than segregated into grade-level and college preparatory classes. One participant remarked, "I think that, like we were talking about, the disciplinary issues and keeping the clusters from forming and traveling together would, I think it would decrease the disciplinary issues that we see. I think it would help those students that have that mentality 'I'm dumb.' I think it would motivate them, because they wouldn't be thinking, 'I'm dumb so I'm in a grade-level class.'”

The second focus group also stated that they would like to blend the two classes. One participant said, "We'd have one, because I feel like if I put the grade-level in with some college preparatory kids, and I wanted to do group work, I could." Another responded, "It's like a whole other level of understanding the concept for them to be able to help somebody that would be in a grade-level that generally wants to learn. And they're able to help them, while I'm able to deal with other kids that need help. The few kids that would be in each class with the poor behaviors, because they would be scattered throughout." Another one stated, "I think if it were more blended, it would be easier on the teachers, and I think the students would get more out of the class."

\section{Conclusions, Implications and Recommendations}

It was apparent through the interviews, focus groups, and observations that there is a disparity in the instructional practices utilized in a grade-level class when compared to a college preparatory class. This sorting system has been in place for over sixty years

and is an ingrained part of the tradition of the school system. Even though the stated goal of the program is to provide differentiated instruction, this goal has not been met. Instead, the system has become a sorting mechanism to separate students based on 
their achievement and behavior. This has led to teachers becoming frustrated with the system and students not receiving the education that they deserve. Teachers clearly stated that they can utilize higher level thinking activities in their college preparatory classes and that they give highly guided direct instruction in their grade-level classes. Furthermore, they noted that students in grade-level classes do not have the opportunity to see what a successful student looks like.

All these findings have great implications for the school district. The first is the fact that the system is not working and is having an adverse effect on academic achievement. It leads to teacher frustration and students associate grade-level classes with a decrease in their ability levels. It limits the schedule by requiring that the two different types of classes be offered for students which helps to keep them segregated throughout the entire day.

Many recommendations can be taken from this study. The first is a recommendation to the school district that they consider doing away with the grade-level and college preparatory system. If the district is unwilling to do away with the system as a whole immediately, they may want to consider starting at the junior high level. This would allow the district to study the academic achievement of the students and amount of discipline. If the district wants to align with the teachers' opinions though, they need to stop utilizing the system altogether. Academic achievement and discipline need to be studied further in this method as well to determine if it is meeting the needs of the students and teachers. This could allow for further studies, including the students' and community members' perceptions of the changes. 


\section{References}

Ansalone, G. (2010). Tracking: Educational differentiation or defective strategy. Educational Research Quarterly, 34(2) 3-17.

Ansalone, G., \& Biafora, F. (2004). Elementary school teachers' perceptions and attitudes to the educational structure of tracking. Education, 125(2), 249-258.

Bernhardt, P. E. (2014). Making decisions about academic trajectories: A qualitative study of teachers' course recommendation practices. American Secondary Education, 42(2), 33-50.

Bell, D. A. (1980). Brown v. board of education and the interest-convergence dilemma. The Harvard Law Review, 93(3), 518-533. doi: 10.2307/1340546

DESE (2016). Missouri district and school information. Retrieved from https://mcds.dese.mo.gov/quickfacts/Pages/District-and-School-Information.aspx

DESE (2016). Missouri learning standards. Retrieved from https://dese.mo.gov/college-career-readiness/curriculum/Missouri-learning$\underline{\text { standards }}$

DESE (2016). Missouri school directory. Retrieved from https://mcds.dese.mo.gov/guidedinquiry/District\%20and\%20School\%20Informati on/Missouri\%20School\%20Directory.aspx

DESE. (2016). Top ten by twenty. Retrieved from https://dese.mo.gov/top-10-by-20

Foley, J. A., Morris, D., Gounari, P., \& Agostinone-Wilson, F. (2015). Critical education, critical pedagogies, Marxist education in the United States. Journal for Critical Education Policy Studies, 13(3), 110-114.

Freire, P. (2000). Pedagogy of the oppressed. (M. Bergman-Ramos, Trans.). New York, 
NY: Continuum. (Original work published 1970)

Hattie, J. (2012). Visible learning: Maximizing impact on learning. New York, NY: Routledge.

Karlson, K. B. (2015). Expectations on track? High school tracking and adolescent educational expectations. Social Forces, 94(1), 115-141. doi:10.1093/sf/sov006

Kelly, S. (2007). The contours of tracking in North Carolina. The High School Journal, 90(4), 15-31.

Kelly, S., \& Carbonaro, W. (2012). Curriculum tracking and teacher expectations:

Evidence from discrepant course taking models. Social Psychology of Education, 15(3), 271-294.doi: 10.1007/s11218-012-9182-6

Modica, M. (2015). My skin color stops me from leading: Tracking, identity, and student dynamics in a racially mixed school. International Journal of Multicultural Education, 17(3), 76-90.

Page, R. (1987). Teachers perceptions of students: A link between classrooms, school cultures, and the social order. Anthropology \& Education Quarterly, 18(2), 7-99.

Rosenthal, R. \& Jacobson, L. (1992). Pygmalion in the classroom: Teacher expectation and Pupils' intellectual development. Williston, VT: Crown House Publishing Limited. 
SECTION FIVE:

CONTRIBUTION TO SCHOLARSHIP 


\section{Contribution to Scholarship}

\section{Introduction}

For well over six decades, a school district in the southeast Midwestern region has had a tracking system in place for assigning students into courses at the junior high and high school levels. This includes grade-level classes, college preparatory classes, and some Advanced Placement classes at the high school level. Prior to beginning seventh grade, the students are not involved in a tracking system to determine course placement. The stated goal of the tracking system is to help provide the differentiation that students need. This system of tracking is ingrained not only in the school but the community itself. Although the stated goal is to help provide differentiation, concerns exist regarding the effectiveness of the tracking system and teachers' perceptions of students in the various tracks. Decisions as to what course students are placed into are based on academic achievement, teacher recommendation, parental requests, and standardized test scores.

Despite the fact these indicators are used to help determine course placement, the tracking system appears to also have become a means to separate students based on discipline and economic status. This is significant because the Midwestern Department of Elementary and Secondary Education (DESE) has launched the Top Ten by Twenty initiative. The Top Twenty initiative is an improvement effort that aims for Midwestern student achievement to be in the top ten of the United States by 2020 (DESE, 2016). A major point of this initiative is that all students will be college and career ready. These reasons are serious considering students in the Midwestern region must complete standardized tests that align with the Midwestern Learning Standards. The Midwestern 
Learning Standards define the knowledge and skills that the state has identified that each student needs to know in each grade-level and course to be successful in college and their careers. The Midwestern Learning Standards are considered to be a road map for educators to use in determining curriculum. Furthermore, they are an instrumental component of the Top Ten by Twenty initiative (DESE, 2016). Students taking gradelevel courses are supposed to receive instruction that meets the standards outlined by the Midwestern Learning Standards. Those involved in college preparatory classes also receive an education that meets the Midwestern Learning Standards while also requiring more rigorous work than grade-level courses do. Those students taking Advanced Placement courses at the high school receive an education that is aligned with the Midwestern Learning Standards while also enabling them to take the Advanced Placement test upon completion of the course.

These standardized tests and standards that all Midwestern students are expected to be able to complete do not differentiate on the material and level of rigor of the assessments. All students complete the same exams even though they may not have been exposed to the same teaching practices when taking grade-level, college preparatory, and Advanced Placement courses.

\section{Organization Demographics}

The study was conducted at a rural junior high and high school located in southeast Midwestern. According to the 2010 United States census, the town had a population of $16,318.69 .95 \%$ of the population was white, $26.20 \%$ was black or African-American alone, $2.01 \%$ were two or more races, and all other races were less than one percent each of the town's population (Census Viewer, 2010). 


\section{Participants}

The participants were teachers from both the junior high and high school. The teachers that participated in the research had a varied amount of experience as they all had the opportunity to participate. An effort was made to obtain a representative sample of the teachers in the district for the focus group and interviews. This included years of experience, level of education obtained, and gender. As of 2016, 250 teachers were employed by the district. They earned on average $\$ 41,173$ per year and had an average of 11.6 years of experience. $44.3 \%$ of the teachers had obtained a Master's degree (DESE, 2016). The individual interviews and focus groups took place in open classrooms. Only the participants and researcher were present during the interviews and focus group sessions. The interviews and focus groups were recorded to allow for the transcription of the sessions afterwards. Observations occurred in the classroom with the researcher scripting what occurred to help identify trends and patterns regarding how instructional strategies are implemented.

The purpose of the study was to examine the instructional strategies that teachers utilize in grade-level and college preparatory classes and how it impacts achievement. Additionally, it examined their expectations of the students in their classrooms.

\section{Research Questions}

The research questions guiding this study were:

1. What impact do various instructional strategies and approaches have on achievement?

2. How does course placement affect instructional behavior and course approaches? 
3. What types of instructional practices are being utilized in classroom instruction for both grade-level and college preparatory classes;

3A. Do they differ and are they equitable?

This study is important for several reasons including the impact it may have on future course placements in the school system and because critical pedagogy and interestconvergence were employed as the conceptual framework, rather than using Oakes' theory of tracking as much of the existing research does. This created a great challenge because course placement has not been studied a great deal through these lenses.

\section{Literature Review}

Ansalone (2010) emphasizes that for almost a century schools have assigned students to various classes based on their "perceived academic ability" (p.3). This differentiation often results in unequal access to knowledge and different treatment of students. Ansalone reviews the fact that there are various forms of tracking that are utilized in schools. There are classes for gifted students which only admit those students based on their perceived ability and there are also special education classes offered for students with learning disabilities. However, most of the tracking in United States schools is between-class groupings. This consists of sorting students into classes of high, average, or low ability. This system was implemented at the beginning of the 1900 s as a way to Americanize immigrants and Southern Blacks who were moving into cities. The reasoning for creating a tracking system was that offering differentiated education would "appropriately socialize the various groups into work roles suitable to their class standing" (p. 4). 
Bernhardt's (2014) work goes further and emphasized that few studies pay attention to the influence that teachers have on students' trajectories. Although he stated that many schools have embraced de-tracking strategies and are attempting to increase enrollment in honors courses, more needs to be done to study the role of teachers in helping accomplish this goal. Using Oakes' theory of de-tracking, Bernhardt found that the teachers had a high level of autonomy in making course recommendations for students. However, this did not come from the teachers' familiarity with students' academic abilities. Instead, it came "from ill-defined expectations, poor communication, and a lack of clear administrative policies" (pp. 41-42).

Morris (2005) also explored how teachers perceived and interacted with their white students in a predominately minority school in Texas. He found that the students' interpretation of their socioeconomic status was a result of how their teachers interpreted their whiteness and how they reacted to the students academically. He found that the teachers related academic ability to social class. The teachers used the term 'middle class' to refer to students who they felt were intelligent. The term 'poor' was used to describe those students that had more obstacles to overcome in their academic pursuits. Modica (2015), however, asserted that the practice of tracking allows racially mixed schools to maintain segregated classrooms. In speaking with students, Modica learned that several students associated being white with academic success. She found that the long-term practice of tracking created racial boundaries among the students, silenced minority students who were in honors courses, and limited the educational opportunities for all students. Efforts to de-track resulted in positive outcomes for all. 
Academic achievement and variances in curriculum are important attributes to consider when studying tracking. Page (1987) found that in lower and regular track classes, curriculum differentiation is not an equitable response to students' interests. Lower track classrooms are those that receive a basic education and higher track classes receive enrichment and get the opportunity to participate in a variety of activities and experiences. Curriculum differentiation in schools with a tracking system is actually a sociocultural and political process. When Page began studying two high schools, she found that poor and minority students were overrepresented in lower track classes. The teachers felt that this separation was important for academic and behavioral concerns because they felt the students did not behave appropriately in class. Teachers' perceptions of the students' social class characteristics were reinforced in the classroom. Those students in the lower track received an education that focused on basic skills, respect, punctuality, and limited discussions. Those in the higher-level track were exposed to a more rigorous curriculum that promoted college readiness.

Student's perceptions about the implementation of a tracking system are important to consider as well. Karlson (2015) studied how students perceive the tracking system and argues that high school students view their track placement as a signal of their abilities and they respond to it by adjusting their own expectations. She examined the consequences of placements in various subjects and investigated the effects of consistent versus discrepant track placements. Results from her study showed that the changes in expectations of students taking honors courses are larger than those in general courses; students tended to regulate their educational expectations based on their track placements. Karlson found that being placed in honors classes in high school positively 
affected students' expectations. In addition to the impact that tracking has on expectations, it has an impact on the stratification of group membership for the students as well as social labeling that is based on cultural assumptions about the individual student's abilities.

Kelly and Carbonaro (2012) went further and attempted to understand the teacherstudent relationship and how teacher expectations of student performance impacted their academic achievement. They found that teacher in higher track classes had higher expectations than the teachers in lower track classrooms. They found three ways in which higher track placement impacted teachers' expectations of their students. First, they believed students identified themselves as college bound and that created consistency in their behavior and performance. Second, the students engaged in similar experiences in other classrooms that teachers viewed as likely to increase their chance of going to college. Third, they found that teachers rely on social categories to define and label students, despite behavior and performance. Teachers found those students in low track classrooms to be frequently disruptive and inattentive due to the lack of incentives for performance in these classes. Furthermore, there was a tendency to be less engaged in school as a way to improve their sense of self-worth. The teachers in low-track classes responded negatively to teaching these courses as well and there was a pattern of negative interactions between them and the students.

In addition to tracking, a great deal of research has been conducted on teachers' expectations of their students. Rosenthal and Jacobsen (1992) emphasized that teachers often believe that middle class children will do well in school while lower class children will struggle. They tested the idea that in a classroom where the teacher expected greater 
growth from students the students would show more growth. Oak School, where the study occurred, had a policy of sorting the students into tracks based primarily on their reading ability. A disproportionate number of Hispanic children were in the lower groups. Although placement into a particular track was based on reading level, the teachers were able to make recommendations as well. The study required that the students participate in an intelligence test. They were later given a posttest as well to measure if there had been any change. In this experiment, the teacher was the agent of change. The teachers had been given a list of twenty percent of their students and told those children were about to excel, but they could not discuss that with the children or their parents. The children on the lists had been selected by a table of random numbers. The difference between the children marked for growth and the control children was actually in the mind of the teachers. Therefore, they surmised that teachers' expectations can be responsible for the students' gains. The researchers referred to this as the Pygmalion effect where an increase in the teachers' expectations led to better performance on the part of the students.

\section{Conceptual Framework}

For the purposes of this study, the researcher studied the practice through the lens of critical pedagogy and interest-convergence. Critical pedagogy questions the power structures that manipulate rationality and truth. It recommends that teachers should act as transformative intellectuals. Also, critical pedagogy requires that teachers promote ideals that are democratic and give students opportunities (Foley, Morris, Gounari, \& Agostinone-Wilson, 2015). Critical pedagogy has roots in political organizing and has shifted more towards a social and educational movement. Tarlau (2014) argues that there 
needs to be a deepened understanding of the relationship between social change and education and that it involves three concepts: the role of social movements in building critical consciousness, links between informal education and social change, and the potential for public schools to make connections to larger movements to promote social justice. Additionally, critical pedagogy emphasizes that schools protect problematic social orders and at the same time can be beacons of hope (Vasallo, 2013).

Furthermore, critical pedagogy values freedom, dignity, and generosity while steering clear of indoctrination and exploitation (Lotier, 2017). Freire emphasized that critical pedagogy is an important component when considering working with an oppressed population; being liberated from oppression is not a gift or an act of selfachievement, rather it is a combination of the two (Freire, 2000). Ford (2014) elaborated by emphasizing that critical pedagogy is a "response to systematic oppression and inequality" (p. 380). He continued to assert that oppression and exploitation occur along the lines of identity and that the identities must be mobilized so the oppression can be revealed.

Additionally, interest-convergence examines the impact of the Brown vs. the Board of Education decision which ruled that separate but unequal was inherently unequal in education. Bell's theory of interest-convergence made the assertion that there was no conflict of interest between the rights of whites to not associate with Blacks and the rights of Blacks to associate with whites. His theory contends that the Brown decision was inevitable. However, more recent court decisions have suggested that integration is less feasible and that a higher quality of education for black students may need to focus on improving existing schools (Bell, 1980). 
Crowder (2014) asserts that poverty has expanded across America which calls for more opportunities to confront questions of inequity. She argues that this has resulted in regional interest convergence which provides a structure to identify various groups and their points of convergence. These can include items such as power imbalances and funding of public schools.

The purpose of this study was to examine the impact that various instructional strategies and approaches have on achievement, how course placement affects instructional behavior and course approaches, and to determine what types of instructional practices are being utilized in classroom instruction for both grade-level and college preparatory class and if they differed or are equitable. In analyzing the data from the interviews, focus groups, and classroom observations, several themes emerged. These included differences in instructional strategies that are utilized in a college preparatory class and not in a grade-level course, lower academic achievement in gradelevel courses, a stigma that is associated with placement in grade-level courses, differences in classroom management styles in the two types of courses, motivation, maturity level, the need for more positive role models in a grade-level course, and a desire to have the students blended rather than separated into the two types of courses.

\section{Findings}

The teachers in the school district showed an obvious commitment to educating their students but quickly acknowledged that having grade-level and college preparatory classes leads them to utilize different instructional strategies in the two types of classes. One junior high teacher stated in regards to her grade-level courses, "I might go a bit slower or use some different material. We have A and B reading study guides. A 
version is supposed to be a bit easier." She further elaborated by saying, "I definitely try to push my grade-level classes. I try not to dummy down the work, so to say. I try to give them the same material. I might present it different or explain it a little better or do a different kind of note-taking strategy than I might with college prep, who might just get it from my saying it. Whereas, a grade-level may not get it unless I explain it differently or we do some type of activity to back that concept up."

These thoughts were apparent in the classrooms where the researcher did observations and scripted what was occurring. Hattie (2012) analyzed the effect size of various instructional strategies on learning and one observation in a grade-level science class quickly illustrated the points made by teachers in interviews and focus groups. The class began with a lot of idle chit chat while the teacher instructed the students to get busy on the bell ringer. The teacher gave frequent reminders to the class to get quiet and work. A new student was present in the class and the teacher explained the procedures for keeping a notebook in the class. The teacher told the student, "Don't use these guys as an example," and pointed to other students sitting near the new student. The teacher began showing a video over weather and the atmosphere and instructed the class to write down fifteen facts about the video in their composition books. He stopped the video at various points and made statements about how things mentioned would be good ideas to write down in the composition book. There was no usage of questions involving deeper levels of thinking. It was direct instruction and the teacher told the students what to write. Throughout the video, many students put their heads down and stayed that way until the teacher went around and told them to sit back up and work. 
The college preparatory classes were quite different than the grade-levels ones. There was an immediate impression of the teacher offering less direction and not making frequent reminders about behavior. One English teacher was conducting a jigsaw assignment. Each student was assigned a question about global warming and had researched facts about their question. They prepared a presentation on their Ipads about their question and shared their findings with the teammates. The students were allowed and encouraged to talk to one another while the teacher walked around listening to the conversations. Additionally, the teacher went over the state standards that applied to the lesson, including speaking and listening. The teacher reminded the class that they were not only being assessed on the material they presented but how they presented it. She went on to state that the students would evaluate one another as well. As the presentations continued, the teacher reminded the class to make sure they cited their material. The teacher then instructed the students to write down something they had learned on a piece of paper and to be specific in their answers. The class then shared out their findings. Finally, the teacher asked the class for feedback on the activity regarding what they liked, what could be done differently, and if they found that they were able to learn more by working with a group of people rather than as individuals. Hattie (2012) found that giving and asking students for feedback had an effect size of .75 and has a high impact on learning. Additionally, the teacher had gone over her expectations for the students which has an effect size of 1.44.

It was also apparent in a college preparatory social studies class that the students and teacher were engaged at a higher level of thinking and interaction. The teacher began a presentation over Islam and asked the students questions that not only required simple 
recall but also that they connect the learning from the current unit with previous units. Connections were also made to artwork, movies, and other forms of media. The teacher passed out a graphic organizer and had the students begin filling it in while she walked around the room inspecting progress and offering assistance. When students would pose questions to her about the culture, the teacher often responded by asking, "What do you know about that?" rather than simply answering. This led to other students getting involved in the discussion and more interaction.

The second focus group emphasized they modify their instruction and assignments for their grade-level classes. One said, "I will try to give more support, I guess you could say. When they do the guided reading, I'm more helpful with them. Helping them learn how to look in the book for the answers, that kind of stuff. On quizzes, I modify the quizzes. So that they don't have the same type.” They also stated that they are unable to do group work in grade-level classes due to behavioral issues. Another participant said, "If we do say, a guided reading type activity, basically, we're going to have to read the text together. We're going to have to read the question together. We're going to have to diagnose that question together to figure out where we can find the answer. But with the college prep, you can say, “'Okay, I'm going to give you ten minutes to read over this section and answer these questions. And then we're going to go over it." Another one stated, "With grade-level, we'll do it together. Like, I will go through it, and we'll find the answers together." This statement was supported by another participant who said if the answer is not exactly the same as the wording on the assignment, the students will say they don't know how to do it. 
One theme that was not as apparent as others but came through in some of the interviews and focus groups was a stigma that is associated with being in a grade-level class. Freire (2000) asserts that dehumanization stops people from becoming fully human. As people struggle to become human, the oppressed person struggles against those who dehumanized them. He went on to state that only power that comes from the oppressed is strong enough to free both groups. This assertion was supported by statements from participants regarding the stigma that students have from being placed in grade-level classes. The first-year high school teacher said, "Honestly, I think that it comes from where there is a stigma attached to grade-level. It's, 'I'm at grade-level, I'm not as smart as everybody else. I don't know how to do this work, it doesn't matter."' He elaborated and said that there is a perception amongst the students in grade-level courses that they are there because they are not smart enough. These assertions were supported by Karlson (2015) who found that students perceive the tracking system as a sign of their abilities and they respond to it by adjusting their own expectations.

This thought was also apparent during the first focus group. One participant stated, “They’ve failed a lot. They’ve had failure...They're just kind of used to it. I feel like failure is what they expect almost more now than not." Another teacher responded, “They've been viewed as that, so that's what they're used to and accustomed to."

A veteran teacher who attended the Springville school district noted the impact as well that moving from a college preparatory class to a grade-level class can have on a student. She noted, "I was in college preparatory history. I didn't do well on a test. The next thing I knew, the teacher gave me a slip that said I had been moved to a grade-level class. I was mortified. None of my friends were in the class. I didn't know anybody. I 
struggled that year. I kept my head down. When my friends saw me going into the room, they asked me why I was in that class. I was so upset that I didn't learn anything that year in that class."

A consistent theme emerged from all participants stating that academic achievement is lower in the grade-level courses than in college preparatory. One teacher emphasized, "My grade-level classes are not successful. [The] majority of them are failing. As a whole class, generally they are doing very poorly. Now, in college prep classes, the majority of them are doing great." The first-year high school teacher stated, "I tend to see lower grades in my grade-level classes. I have a bunch of people that are failing."

The first focus group emphasized the difference in academic achievement by pointing out that in a college preparatory class if they pose a discussion question, someone will have a comment about it while students in grade-level classes will just stare at them. The second focus group pointed out that they have lower grades in their gradelevel classes and that it is mostly due to missing work. One said, "I can sit and give them a piece of paper with five questions and I can go through every single answer on the paper and give it to them word for word. Repeat it twenty times, and they just won't write it down." This point was emphasized by all the participants in the second focus group. One person said, "And I tell them, I do this genuinely just for you to boost your grade. If you got a bad grade on the test, here's this. And we do it every Friday, and every Friday, my seventh hour and my second hour, I'll get, maybe, three or four of them done." 
Kelly and Carbonaro's (2012) assertions that teachers in lower track classes found students to be disruptive and inattentive were apparent in the interviews and focus groups. The participants emphasized that they must maintain stricter control in their grade-level classes as compared to their college preparatory ones. One teacher stated that, “...takes away from those who are truly grade-level and truly need some extra help because I'm dealing with the ones who don't want to behave, that just want to goof off, and whatever. My grade-level classes completely wear me out. I'm completely exhausted. I have to watch their every move. I have to be up and at it constantly. I cannot trust them to work independently. I have to basically constantly monitor what's going on, whereas my college prep classes, I don't worry about them so much. I mean, they're responsible, and they get to work and they do what they're supposed to do. Yes, I walk around the room, and yes, I check on them, but not as intensely as I would with my grade-level class.”

One participant also noted achievement dropped when a student was moved from her college preparatory class to a grade-level one. She emphasized, "The counselor told me that the student's mother wanted her moved to grade-level. I was confident that she could handle the work in college preparatory and that is where she needed to be. She had already completed assignments for me and was doing very well. The counselor said she didn't have a choice; the student's mother wanted her moved, so she made the change. I saw a change in the student right away. She began to act out in class, not complete assignments, and the overall quality of her work was not as good as it had been prior to her being moved. I've even had students tell me when they've been moved from college 
preparatory to grade-level that the reason their grade drops is that they can't appear to be smart in front of their peers."

Bell's (1980) theory of interest-convergence was also apparent in the participants' point that there is a need for role models. Interest-convergence argues that change is not necessarily based on race but rather what is needed to advance a cause because it is advantageous for both populations. The need for role models emerged as a theme when teachers were asked why a problem with motivation existed in the grade-level classes. When one teacher was asked why she believed the students were not motivated, she responded, "Well, in my opinion, being in a grade-level class does not help create a motivational setting. When you have the kids mixed in, college prep with grade-level together in one class, they can see others doing what they're supposed to be doing, and when they're all in the grade-level class, they tend to feed off of one and other, and when one is being goofy, then they all want to be goofy. There's no one to boost morale or to be the leader in a positive way."

All participants expressed a desire to do away with the system of having gradelevel and college preparatory classes. While they were not aware of all of the research that existed that supports doing away with the tracking system, their arguments aligned with Freire's (2000) argument that being liberated from oppression is not a gift or an act of self-achievement, instead it is a combination of the two. One teacher stated regarding the current system, "I don't like it. I think it makes our job a little harder, especially in those grade-level classes. I feel if they were evenly distributed throughout all the classes that we probably wouldn't have such a behavior issue in the grade-level issue. They would be separated out, and they would see kids who are being good, and be discouraged 
for acting silly." She also made an observation regarding when she has been able to group a lower ability student with a higher one, stating, "I did notice that some of my lower kids, I could group them with one of my higher kids, and they would just really take to him. And my higher kids wanted to take them under their wing, and help them out, and be their little teacher on the side or whatever, so that helped a lot with academic things."

Another teacher noted that blending the classes would enable them to utilize more instructional strategies such as team building, small group lessons, and an increase in desired behaviors. "I think that blending the kids together at the grade-level and college preparatory, I think you would get more of the good behaviors out of the lower kids. I don't think they would behave the same way in front of a group of kids that are intellectually not challenged." When asked if she had ever had a student moved from grade-level to college preparatory and how it went, she responded, "Typically, when you move them up, they look at it as an accomplishment or a success and they want to prove to you that they can and it's successful."

The veteran teacher who is a product of the school system noted, "I am used to the whole grade-level, college prep. I was raised that way. I went through school with both of those levels and my first ten years or so teaching I totally agreed with keeping them separate because it was two different books, completely different books. The grade-level book that those children used was a lot easier. It did not take them as far. It still covered the same subjects as the college prep book but did not go quite as far. Not as many word problems or where they had to actually apply. When we started using the same books and I don't remember what year that was it didn't take me but about one 
school year to realize that we didn't need to separate these children teaching the exact same stuff. We don't need all grade-level in one class and college prep in another and that's when my thinking changed." A first-year teacher who also attended the school echoed this thinking. He stated, "I don't know if combined I guess is the word I need to use. I'd prefer it if they were just all together. Because I know when I was in class, like I said I was in college prep, AP, I was never top of the class. I was always a smart student. I was always keeping up, but there were people that I could turn to like, 'Hey, I need help with this." This idea was reiterated by a participant in the first focus group who noted that in one instance when she had a low performing student in a college preparatory class, "I always tried to partner him up with student that I knew could help him. What I found from doing that was actually that the other student benefited as well because you learn something the best when you teach it."

It was apparent through the interviews, focus groups, and observations that there is a disparity in the instructional practices utilized in a grade-level class when compared to a college preparatory class. This sorting system has been in place for over sixty years and is an ingrained part of the tradition of the school system. Even though the stated goal of the program is to provide differentiated instruction, this goal has not been met. Instead, the system has become a sorting mechanism to separate students based on their achievement and behavior. This has led to teachers becoming frustrated with the system and students not receiving the education that they deserve. Teachers clearly stated that they can utilize higher level thinking activities in their college preparatory classes and that they give highly guided direct instruction in their grade-level 
classes. Furthermore, they noted that students in grade-level classes do not have the opportunity to see what a successful student looks like.

\section{Implications and Recommendations}

All these findings have great implications for the school district. The first is the fact that the system is not working and is having an adverse effect on academic achievement. It leads to teacher frustration and students associate grade-level classes with a decrease in their ability levels. It limits the schedule by requiring that the two different types of classes be offered for students which helps to keep them segregated throughout the entire day.

Many recommendations can be taken from this study. The first is a recommendation to the school district that they consider doing away with the grade-level and college preparatory system. If the district is unwilling to do away with the system as a whole immediately, they may want to consider starting at the junior high level. This would allow the district to study the academic achievement of the students and amount of discipline. If the district wants to align with the teachers' opinions though, they need to stop utilizing the system altogether. Academic achievement and discipline needs to be studied further in this method as well to determine if it is meeting the needs of the students and teachers. This could allow for further studies, including the students' and community members' perceptions of the changes. 


\section{References}

Ansalone, G. (2010). Tracking: Educational differentiation or defective strategy. Educational Research Quarterly, 34(2) 3-17.

Bernhardt, P. E. (2014). Making decisions about academic trajectories: A qualitative study of teachers' course recommendation practices. American Secondary Education, 42(2), 33-50.

Bell, D. A. (1980). Brown v. board of education and the interest-convergence dilemma. The Harvard Law Review, 93(3), 518-533. doi: 10.2307/1340546

Census Viewer (2010). Sikeston, Missouri population: Census 2010 and 2000 interactive map, demographics, statistics, quick facts. Retrieved from http://censusviewer.com/city/MO/Sikeston

Crowder, P. A. (2014). Suburban poverty and regional interest convergence. Marquette Law Review, 98(2), 763-830.

DESE (2016). Missouri district and school information. Retrieved from https://mcds.dese.mo.gov/quickfacts/Pages/District-and-School-Information.aspx

DESE (2016). Missouri learning standards. Retrieved from https://dese.mo.gov/college-career-readiness/curriculum/Missouri-learning$\underline{\text { standards }}$

DESE (2016). Missouri school directory. Retrieved from https://mcds.dese.mo.gov/guidedinquiry/District\%20and\%20School\%20Informati on/Missouri\%20School\%20Directory.aspx

DESE. (2016). Top ten by twenty. Retrieved from https://dese.mo.gov/top-10-by-20

Foley, J. A., Morris, D., Gounari, P., \& Agostinone-Wilson, F. (2015). Critical education, 
critical pedagogies, Marxist education in the United States. Journal for Critical Education Policy Studies, 13(3), 110-114.

Ford, D. R. (2014). A critical pedagogy of ineffability: Identity, education and the secret life of whatever. Educational Philosophy and Theory, 46(4), 380-392. doi:10.1080/00131857.2013.779218

Freire, P. (2000). Pedagogy of the oppressed. (M. Bergman-Ramos, Trans.). New York, NY: Continuum. (Original work published 1970)

Hattie, J. (2012). Visible learning: Maximizing impact on learning. New York, NY: Routledge.

Karlson, K. B. (2015). Expectations on track? High school tracking and adolescent educational expectations. Social Forces, 94(1), 115-141. doi:10.1093/sf/sov006

Kelly, S., \& Carbonaro, W. (2012). Curriculum tracking and teacher expectations: Evidence from discrepant course taking models. Social Psychology of Education, 15(3), 271-294.doi: 10.1007/s11218-012-9182-6

Lotier, K. M. (2017). On not following Freire: Foucault and the critique of human capital. Modica, M. (2015). My skin color stops me from leading: Tracking, identity, and student dynamics in a racially mixed school. International Journal of Multicultural Education, 17(3), 76-90.

Morris, E. W. (2005). From middle class to trailer trash: Teachers' perceptions of white students in a predominately minority school. Sociology of Education, 78(2), 99121.

Page, R. (1987). Teachers perceptions of students: A link between classrooms, school cultures, and the social order. Anthropology \& Education Quarterly, 18(2), 77-99. 
Rosenthal, R. \& Jacobson, L. (1992). Pygmalion in the classroom: Teacher expectation and Pupils' intellectual development. Williston, VT: Crown House Publishing Limited. (Original work published 1968)

Tarlau, R. (2014). From a language to a theory of resistance: Critical pedagogy, the limits of "framing," and social change. Educational Theory, 64(4), 369-392.

Vasallo, S. (2013). Critical pedagogy and neoliberalism: Concerns with teaching selfregulated learning. Studies in Philosophies \& Education, 32(6), 563-580. doi:10.1007/s11217-012-9337-0 


\section{SECTION SIX:}

SCHOLARLY PRACTITIONER REFLECTION 


\section{Scholarly Practitioner Reflection}

\section{Introduction}

My practice as an educational leader has been greatly impacted by being a member of Cohort 10. I will never forget the summer of 2015. Every time that Dr. Simmons stood up and began lecturing, I was absolutely riveted, soaked up her words, and thought about how they were applicable to my work and actions. I found myself viewing things more consciously through the lens of social justice and spoke out against things that I felt were detrimental to our students. This often went against the grain of what people thought should occur, but I felt strongly that the status quo needed to be challenged for the benefit of our students. That summer was what set into motion my decision to conduct this study.

\section{Influence as Educational Leader}

Questioning methods that have been in place since at least 1955 in a school and community that values tradition as the one the study was employed in is not without its hazards but through careful questioning, I was able to help others see that we needed to examine our practices and determine if they were best for our students. When I found out that the practice of separating the students into grade-level and college preparatory classes had been in place since at least 1955, I knew one very important question needed to be posed. I asked the superintendent if the practice was a reaction to Brown vs. the Board of Education since the decision was handed down in 1954. The superintendent's face changed dramatically and he told me that he did not know, but if I found out to let him know. I then realized that many things might be in place for reasons that no one truly understands. 


\section{Influence as Scholar}

Furthermore, this degree has impacted me as a scholar as well. I find myself frequently asking what does the research state, is it peer-reviewed, have all the possible angles been explored, and what lens did the person view the problem through. This has led me to review things for my own understanding. One day while giving a presentation to several key members of the school district, a person stated to me that the research did not support the assertions I was making. Due to the time and training that I had gone through with this program, I knew that was not the case and that the research they were indicating was not sound. I was able to refocus the conversation so we could make strides to improve education for our students. I would not have been as confident responding to those statements if I had not learned the proper methodology for conducting and reviewing research.

I have also grown as a scholar through my understanding of the benefits working with a team of researchers can have. When I entered this program, I did not mind group work necessarily, but I always worried about whether people would pull their fair share of the load. I was very fortunate to work in fantastic groups during both summers in Columbia and in Cape Girardeau. I found that it is imperative to include other viewpoints in our research and that oftentimes people in other careers have very valid points that need to be considered. Having the opportunity to work with people in higher education was invaluable. It enabled me to better understand what they needed students to be able to do. I was able to transfer that knowledge to my practice in the kindergarten through twelfth grade realm. Additionally, it gave me a great pool of people to consult with on matters of education throughout the region and state. 
Finally, this program has enabled me to understand the importance of analyzing policies and determining the best way to frame new programs. As I finished this degree, I was presented with a unique opportunity to help build a program from the ground up in our district and work with students to help realize their full potential in other avenues than traditional school. Ten years ago, I likely would have viewed virtual education as a joke. However, this program has taught me to look at all the various components and make a decision that is based on data rather than feelings. I know I will be able to take what I have learned through this program and apply it to my work to create a sustainable program that will benefit the district's students and community. 
REFERENCES 


\section{References}

Ansalone, G. (2010). Tracking: Educational differentiation or defective strategy. Educational Research Quarterly, 34(2) 3-17.

Ansalone, G., \& Biafora, F. (2004). Elementary school teachers' perceptions and attitudes to the educational structure of tracking. Education, 125(2), 249-258.

Archbald, D., \& Keleher, J. (2008). Measuring conditions and consequences of tracking in the high school curriculum. American Secondary Education, 36(2), 26-42.

Baoyan, Y., \& Minggang, W. (2015). Changes in urban-rural social structure and distribution of high school educational opportunities — an analysis based on middle school graduation education tracking in Q County, Gansu. Chinese Education \& Society, 48(6), 433-452. doi: 10.1080/10611932.2015.1119509

Bell, D. A. (1980). Brown v. board of education and the interest-convergence dilemma. The Harvard Law Review, 93(3), 518-533. doi: 10.2307/1340546

Bernhardt, P. E. (2014). Making decisions about academic trajectories: A qualitative study of teachers' course recommendation practices. American Secondary Education, 42(2), 33-50.

Bolman, L. G. \& Deal, T. E. (2013). Reframing organizations: Artistry, choice, and leadership. San Francisco, CA: Jossey-Bass.

Castro, E. L. \& Brawn, M. (2017). Critiquing critical pedagogies inside the prison classroom: A dialogue between student and teacher. Harvard Educational Review, 87(1), 99-121.

Census Viewer (2010). Sikeston, Missouri population: Census 2010 and 2000 interactive map, demographics, statistics, quick facts. Retrieved from 
http://censusviewer.com/city/MO/Sikeston

Creswell, J. W. (2014). Research design: Qualitative, quantitative, and mixed methods approaches. Thousand Oaks, CA: SAGE Publications, Inc.

Crowder, P. A. (2014). Suburban poverty and regional interest convergence. Marquette Law Review, 98(2), 763-830.

DESE (2016). Missouri district and school information. Retrieved from https://mcds.dese.mo.gov/quickfacts/Pages/District-and-School-Information.aspx

DESE (2016). Missouri learning standards. Retrieved from https://dese.mo.gov/college-career-readiness/curriculum/Missouri-learning$\underline{\text { standards }}$

DESE (2016). Missouri school directory. Retrieved from https://mcds.dese.mo.gov/guidedinquiry/District\%20and\%20School\%20Informati on/Missouri\%20School\%20Directory.aspx

DESE. (2016). Top ten by twenty. Retrieved from https://dese.mo.gov/top-10-by-20

Dimick, A. S. (2016). Exploring the potential and complexity of a critical pedagogy of place in urban science education. Science Education, 100(5), 814-836. doi: $10.1002 /$ sce. 21233

ESSA. (2015). Every student succeeds act. Retrieved from https://www.ed.gov/ESSA Fink, A. (2017). How to conduct surveys: A step-by-step guide. Los Angeles, CA: Sage. Foley, J. A., Morris, D., Gounari, P., \& Agostinone-Wilson, F. (2015). Critical education, critical pedagogies, Marxist education in the United States. Journal for Critical Education Policy Studies, 13(3), 110-114.

Ford, D. R. (2014). A critical pedagogy of ineffability: Identity, education and the secret 
life of whatever. Educational Philosophy and Theory, 46(4), 380-392.

doi:10.1080/00131857.2013.779218

Freire, P. (2000). Pedagogy of the oppressed. (M. Bergman-Ramos, Trans.). New York, NY: Continuum. (Original work published 1970)

Gilborn, D. (2013). Interest-divergence and the colour of cutbacks: race, recession, and the undeclared war on black children. Discourse: Studies in the Cultural Politics of Education, 34(4), 477-491. doi: 10.1080/01596306.2013.822616

Grenier, F. (2016). How can reflexivity inform critical pedagogies? Insights from the theory versus practice debate. International Studies Perspectives, 17(2), 154-172. doi: 10.1093/isp/ekv006

Hantzopoulos, M. (2015). Sites of liberation or sites of despair? The challenges and possibilities of democratic education in an urban public school in New York City. Anthropology and Education Quarterly, 46(4), 345-362. doi:10.1111/aeq.12115

Hattie, J. (2012). Visible learning: Maximizing impact on learning. New York, NY: Routledge.

JCEPS. (2018) Submissions and style guidelines. Retrieved from http://www.jceps.com/submissions

Karakowsky, L., DeGama, N., \& McBey, K. (2012). Facilitating the Pygmalion effect: The overlooked role of the subordinate perceptions of the leader. Journal of Occupational and Organizational Psychology, 85, 579-599.

Karlson, K. B. (2015). Expectations on track? High school tracking and adolescent educational expectations. Social Forces, 94(1), 115-141. doi:10.1093/sf/sov006

Kelly, S. (2007). The contours of tracking in North Carolina. The High School Journal, 
90(4), 15-31.

Kelly, S., \& Carbonaro, W. (2012). Curriculum tracking and teacher expectations: Evidence from discrepant course taking models. Social Psychology of Education, 15(3), 271-294.doi: 10.1007/s11218-012-9182-6

Krueger, R. A., \& Casey, M. A. (2015). Focus groups: A practical guide for applied research (5th ed.). Los Angeles, CA: Sage.

Lotier, K. M. (2017). On not following Freire: Foucault and the critique of human capital. Pedagogy, 17(2), 151-175.

Marzano, R. J. (2003). What works in schools: Translating research into action (1st ed.). Alexandria, VA: ASCD.

Merriam, S. B., \& Tisdell, E. J. (2016). Qualitative research: A guide to design and implementation (4th ed.). San Francisco, CA: Jossey-Bass.

Modica, M. (2015). My skin color stops me from leading: Tracking, identity, and student dynamics in a racially mixed school. International Journal of Multicultural Education, 17(3), 76-90.

Morris, E. W. (2005). From middle class to trailer trash: Teachers' perceptions of white students in a predominately minority school. Sociology of Education, 78(2), 99121.

Northouse, P. E. (2016) Leadership Theory and Practice. (7th ed.) Los Angeles, CA: SAGE.

Page, R. (1987). Teachers perceptions of students: A link between classrooms, school cultures, and the social order. Anthropology \& Education Quarterly, 18(2), 77-99.

Rosenthal, R. \& Jacobson, L. (1992). Pygmalion in the classroom: Teacher expectation 
and Pupils' intellectual development. Williston, VT: Crown House Publishing Limited. (Original work published 1968)

Shaunessy-Dedrock, E., Suldo, S. M., Roth, R. A., \& Fefer, S. A. (2014). Student's perceptions of factors that contribute to risk and success in accelerated high school courses. The University of North Carolina Press, 98(2), 109-137.

Shor, I. (2009). Critical pedagogy is too big to fail. Journal of Basic Writing, 28(2), 6-27.

Sikeston R-6. (2018). District information CSIP plan. Retrieved from http://sikestonr6.org/119596_2

Tarlau, R. (2014). From a language to a theory of resistance: Critical pedagogy, the limits of "framing," and social change. Educational Theory, 64(4), 369-392.

United States Department of Health and Human Services. (2016). Institutional review boards frequently asked questions. Retrieved from https://www.fda.gov/RegulatoryInformation/Guidances/ucm126420.htm

Vasallo, S. (2013). Critical pedagogy and neoliberalism: Concerns with teaching selfregulated learning. Studies in Philosophies \& Education, 32(6), 563-580. doi:10.1007/s11217-012-9337-0

Van Houtte, M., Demanet, J., \& Stevens, P. A. (2013). Curriculum tracking and teacher evaluations of individual students: Selection, adjustment or labeling? Social Psychology of Education, 16(3), 329-352. doi: 10.1007/s11218-013-9216-8

Van Houtte, M., \& Stevens, P. A. (2015). Tracking and sense of futility: The impact of between-school tracking in secondary education in Flanders. British Educational Research Association, 41(5), 782-800.

Willink, K. (2008). Economy and pedagogy: Laboring to learn in Camden County, North 
Carolina. Communication and Critical/Cultural Studies, 5(1), 64-86. doi: $.1080 / 14791420701821781$ 
APPENDIX 


\section{Interview Protocol}

Date:

Location of the interview:

Name of interviewee:

Script for the interviewer to follow:

Thank you for agreeing to participate in this interview. I greatly appreciate your time and willingness to discuss the impact that course placement has on instructional practices. I am going to be asking you some questions about this system. If something does not make sense, please stop me at any time and I will explain it further. This is the informed consent which outlines the research. What we discuss here today will be kept confidential. You will not be identified, and I will keep this recording secure. The information that I gather will be included in research and may be published. Please take a look at it and if you are willing, go ahead and sign the form. After the form is signed, tell the participant that I would like to start out by getting to know them a little better.

1. Tell me about your background as an educator. How long have you been teaching? How many years have you taught in this school system? What subject area do you teach?

2. How do you approach teaching a college preparatory class and a grade-level class?

3. Tell me about ways that you differentiate your instruction in grade-level and college preparatory classes.

4. What type of impact do you see on achievement when you compare a grade-level and college preparatory class? 
5. Tell me your thoughts on the ways that dividing students into grade-level and college preparatory has on a teacher's decisions regarding what instructional strategies to utilize in the classes.

6. Tell me about your thoughts regarding an individual student's abilities based on his or her course placement.

7. Please describe your opinions regarding separating students into grade-level and college preparatory classes.

Follow up prompts that may be interspersed between questions one through seven, depending on responses, may include items such as the following: What types of instructional materials are selected? How does your classroom management style vary between the two different course types? What types of assignments do you give in the two courses? How do you utilize direct instruction? How do you implement projectbased learning in your classroom?

8. Is there anything else you would like to share with me regarding grade-level and college preparatory course placement?

Script to follow for closing the interview:

Thank you again for participating in this interview. Your input has been a great help and I enjoyed speaking with you. If you have any questions, please feel free to contact me. Here is another copy of my phone number and email address. 


\section{Focus Group Protocol}

Date:

Location of the focus group:

Names of focus group participants:

Script for the interviewer to follow:

Thank you all for agreeing to participate in this focus group. I greatly appreciate your time and willingness to discuss the impact that course placement has on instructional practices. I am going to be asking you some questions about the ways this system impacts the culture and climate of the school. If something does not make sense, please stop me at any time and I will explain it further. This is the informed consent which outlines the research. What we discuss here today will be kept confidential. You will not be identified, and I will keep this recording secure. The information that I gather will be included in research and may be published. Please take a look at it and if you are willing, go ahead and sign the form. After the form is signed, tell the participants that I would like to start out by getting to know them a little better.

1. Tell me about yourselves. How long have you been teaching? How long have you taught for this school system? What subject areas do you teach?

2. Tell me about the ways that the culture of the school is impacted by separating students into grade-level and college preparatory classes.

3. What type of climate exists in a grade-level class compared to a college preparatory class?

4. Please describe what instruction looks like in a grade-level class compared to a college preparatory class. 
5. Tell me about the ways teachers approach teaching a grade-level class.

6. How do teachers approach teaching a college preparatory class?

7. Tell me about the perceptions that exist concerning a grade-level class and a college preparatory class.

Follow up prompts may be asked between questions one through seven depending on the participants' responses. This may include items such as: Tell me why the instructional approaches used in the two courses differ. Give examples of the ways you have seen the culture and climate change throughout the course of a school year in these two

courses. Tell me about ways you believe will improve student achievement and climate in these two courses.

8. Is there anything else you would like to share with me regarding grade-level and college preparatory course placement?

Script to follow for closing the interview:

Thank you again for participating in this focus group. Your input has been a great help and I enjoyed speaking with you. If you have any questions, please feel free to contact me. Here is another copy of my phone number and email address. 


\section{Classroom observation protocol}

Date:

Location of the observation:

Name of teacher in the classroom:

Name and class period of the course:

Script for the researcher to follow:

Thank you all for agreeing to let me observe your class today. I greatly appreciate your time and willingness to let me observe the impact that course placement has on instructional practices. I am going to be observing the class and noting what instructional strategies are being utilized. I will not interrupt the class or speak to you or your students during the lesson. What I observe here today will be kept confidential. You will not be identified, and all of my notes will be kept in a secure location. Here is a copy of the informed consent. Please take a look at it and if you are willing, go ahead and sign the form. After the form is signed, thank the participant again and begin the observation at the start of the class.

Instructions for the observer to follow during the observation:

Take extensive notes during the observation using scripting techniques. Any time a different instructional technique is utilized, make a notation of it and the time it begins and ends. 
IRB 2011694

\section{University of Missouri-Columbia}

\section{Informed Consent}

This informed consent is for teachers in the Sikeston R-6 school district who I am inviting to participate in research titled "Teacher Perceptions Regarding Course Placement."

Principal researcher: Jodi Glidewell

Organization: University of Missouri-Columbia

Name of project: Course Placement and Instructional Strategies Utilized in the Classroom

This Informed Consent Form has two parts:

- Information Sheet (to share information about the study with you)

- Certificate of Consent (for signatures if you choose to participate)

You will be given a copy of the full Informed Consent Form

\section{Part I: Information Sheet}

Introduction

I am doing research to determine what instructional strategies are utilized in grade-level and college preparatory classes and the impact it has on achievement. I am inviting you to be part of this research. You do not have to participate in the research. Before you make your decision, you can talk to anyone you would like about the research. Please stop me at any time as we go through this information to ask any questions you have, and I will answer them. If you have any questions later, you can ask them of me.

\section{Purpose of the research}

The classes that students take at school are very important. I want to learn what impact there is on based on students being placed in grade-level and college preparatory classes. I believe that you can help me by telling me what instructional strategies you utilize in your classroom and the impact it has on achievement. I want to know more about this because this knowledge may help us to learn if there are better ways to assign students to classes.

\section{Type of Research Intervention}

This research will involve your participation in a one-hour interview.

\section{Participant Selection}

You were invited to participate in this research because I feel your experience as a teacher can help me better understand the thoughts about student placement.

\section{Voluntary Participation}


Your participation in this research is entirely voluntary. It is your choice whether or not to participate. Your choice will have no bearing on your job. You may change your mind and stop participating.

\section{Procedures}

A. You are being asked to help me learn more about instructional strategies utilized in grade-level and college preparatory classes at Sikeston R-6. I am inviting you to take part in this research project. If you accept, you will be asked to participate in an interview or a focus group.

During the interview or focus group, I will sit down with you and ask you some questions. If you do not wish to answer any of the questions during the interview, you may say so, and I will move on to the next question. No one else but me will be present unless you would like someone else to be there. The information recorded is confidential; no one except me, the College of Education IRB, and personnel particular to this research have access to the records. The entire interview will be recorded, but no one will be identified by name on the recording. The recording will be kept in a locked filing cabinet. The information recorded is confidential and the tapes will be destroyed after ten weeks.

\section{Duration}

The research takes place over one day. During that time, I will interview you for about an hour.

\section{Risks}

Risks or discomforts are minimal in this research project.

\section{Benefits}

There will be no direct benefit to you, but your participation is likely to help me find out more about the impact of course placement in the Sikeston R-6 school district.

\section{Confidentiality}

The research being done in the school may draw attention and if you participate you may be asked questions by other people. I will not be sharing information about you to anyone. The information I collect from this research project will be kept private. Any information about you will have a number on it instead of your name. I will be the only one that knows what your number is and will lock that information up in a filing cabinet. It will not be shared with or given to anyone.

\section{Sharing the Results}

Nothing that you tell me today will be shared with anybody, and nothing will have your name on it. The knowledge that I get from this research will be shared with you before it is made 
widely available to the public. Each participant will receive a summary of the results. Following this, the research will be published so other people may learn from it.

\section{Right to Refuse or Withdraw}

You do not have to take part in this research if you do not wish to do so and choosing to participate will not affect your job. You may stop participating in the interview at any time that you wish without your job being affected.

\section{Who to Contact}

If you have any questions, you can ask them now or later. If you wish to ask questions later, you may contact me at (573) 703-7416 or email jjagyz2@mail.Missouri.edu. This proposal has been reviewed and approved by the University of Missouri's IRB which is a committee whose job it is to make sure that research participants are protected from harm.

\section{Part II: Certificate of Consent}

I have been invited to participate in research about teacher perceptions regarding course placement.

I have read the foregoing information, or it has been read to me. I have had the opportunity to ask questions about it and any questions I have been asked have been answered to my satisfaction. I consent voluntarily to be a participant in this study

Print Name of Participant

Signature of Participant

Date

Day/month/year

Statement by the researcher/person taking consent

I have accurately read out the information sheet to the potential participant, and to the best of my ability made sure that the participant understands that the following will be done:

1. All information will be kept confidential.

2. The participants understand they may withdraw at any time.

I confirm that the participant was given an opportunity to ask questions about the study, and all the questions asked by the participant have been answered correctly and to the best of my ability. I confirm that the individual has not been coerced into giving consent, and the consent has been given freely and voluntarily.

A copy of this ICF has been provided to the participant.

Print Name of Researcher/person taking the consent 
Signature of Researcher /person taking the consent

Date

Day/month/year 


\section{Vita}

Jodi Glidewell was born on June 10, 1978, in Boonville, Missouri. She lived in Fayette, Missouri until her family moved to Conway, Missouri prior to starting kindergarten. Jodi attended Laclede County R-1 schools from kindergarten through twelfth grade. Her time there helped to establish her love for education and a desire to become a teacher. Jodi attended Missouri State University for her undergraduate degree in education, with majors in history and English from 1996-2000. She then pursued her Master's in educational administration from Missouri State University from 20012005. Jodi became a high school English teacher at Sikeston High School in 2002. She rose to the ranks of a high school administrator in 2008 and then transferred to the junior high in 2009. From 2012-2014, Jodi attended Southeast Missouri State University where she earned her Specialist's degree in education administration. In 2015, Jodi began attending the University of Missouri-Columbia to earn her Doctorate of Educational Leadership and Policy Analysis. She resides and works in Sikeston, Missouri. 